\title{
Spray Drying for the Preparation of Nanoparticle-Based Drug Formulations as Dry Powders for Inhalation
}

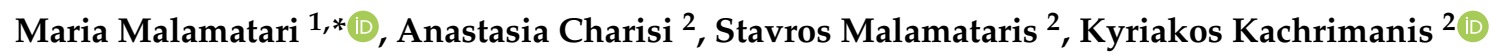 \\ and Ioannis Nikolakakis ${ }^{2}$ (D) \\ 1 Department of Pharmaceutics, UCL School of Pharmacy, 29-39 Brunswick Square, London WC1N 1AX, UK \\ 2 Department of Pharmaceutical Technology, School of Pharmacy, Faculty of Health Sciences, \\ Aristotle University of Thessaloniki, 54124 Thessaloniki, Greece; charissian@gmail.com (A.C.); \\ smalam@pharm.auth.gr (S.M.); kgk@pharm.auth.gr (K.K.); yannikos@pharm.auth.gr (I.N.) \\ * Correspondence: maria.malamatari.12@ucl.ac.uk
}

Received: 26 May 2020; Accepted: 30 June 2020; Published: 6 July 2020

check for updates

\begin{abstract}
Nanoparticle-based therapeutics have been used in pulmonary formulations to enhance delivery of poorly water-soluble drugs, protect drugs against degradation and achieve modified release and drug targeting. This review focuses on the use of spray drying as a solidification technique to produce microparticles containing nanoparticles (i.e., nanoparticle (NP) agglomerates) with suitable properties as dry powders for inhalation. The review covers the general aspects of pulmonary drug delivery with emphasis on nanoparticle-based dry powders for inhalation and the principles of spray drying as a method for the conversion of nanosuspensions to microparticles. The production and therapeutic applications of the following types of NP agglomerates are presented: nanoporous microparticles, nanocrystalline agglomerates, lipid-based and polymeric formulations. The use of alternative spray-drying techniques, namely nano spray drying, and supercritical $\mathrm{CO}_{2}$-assisted spray drying is also discussed as a way to produce inhalable NP agglomerates.
\end{abstract}

Keywords: drug nanoparticles; dry powder inhalers; nanoparticle agglomerates; pulmonary drug delivery; spray drying

\section{Introduction}

Pulmonary Drug Delivery Using Dry Powder Inhalers

Drug delivery to the lungs is an effective way of targeting inhaled therapeutic aerosols for the treatment of respiratory diseases such as asthma, chronic obstructive pulmonary disorder (COPD), cystic fibrosis, lung cancer and pulmonary arterial hypertension. The large surface area $\left(\sim 100 \mathrm{~m}^{2}\right)$ available for absorption, their lower metabolic activity compared to the liver and the gastrointestinal tract, the abundance of capillaries and the thin air-blood barrier, make the lungs an ideal portal of entry for the systemic drug delivery of small molecules, but also biopharmaceuticals including peptides (e.g., insulin), proteins, small interfering Ribose Nucleic Acid (RNA, siRNA) and vaccines (e.g., avian influenza vaccine) [1].

Except for medical gases and administration by intratracheal instillation, a drug must be presented as an aerosol (i.e., a colloidal dispersion of liquid droplets or solid particles in gases with sufficient kinetic stability as a suspension) in order to be delivered to the lungs.

Particle size is the main determinant in the deposition of inhaled aerosols within the lungs. The particle size distribution of an aerosol is usually expressed by its mass median aerodynamic diameter (MMAD). The location of the deposition of the particles within the respiratory tract is analogous to 
their size. Particles of high MMAD inhaled at high velocity are deposited in the airway bifurcation by impaction, while smaller particles are deposited deeper in the lungs (i.e., in the small airway) by sedimentation and impaction. Periods of breath-holding can enhance the deposition by the latter two mechanisms as they allow more time for particles with low settling velocity to deposit [2]. It is often stated that due to their low settling velocity, submicron particles are exhaled. However, counter balancing the greater risk of breathing out, submicron particles have the capacity to be distributed throughout the lungs and reach the distal airways [3]. It has been reported that optimum alveolar deposition can be achieved for two distinct particle sizes; $\sim 3 \mu \mathrm{m}$ and smaller than $50 \mathrm{~nm}$ by sedimentation and diffusion respectively [4].

Delivery of a dry powder formulation to the lungs for local or systemic drug effect is achieved by using specific devices known as dry powder inhalers (DPIs). They are the fastest-growing segment of the asthma and COPD devices market [5] and the foreseeable phasing down of hydrofluoroalkane propellants due to climatic changes is expected to further boost their development.

DPIs can be classified into three main categories; the breath-actuated single unit-dose devices, the breath-actuated multi-dose and the active devices. Examples of devices belonging to each category are presented in Figure 1.

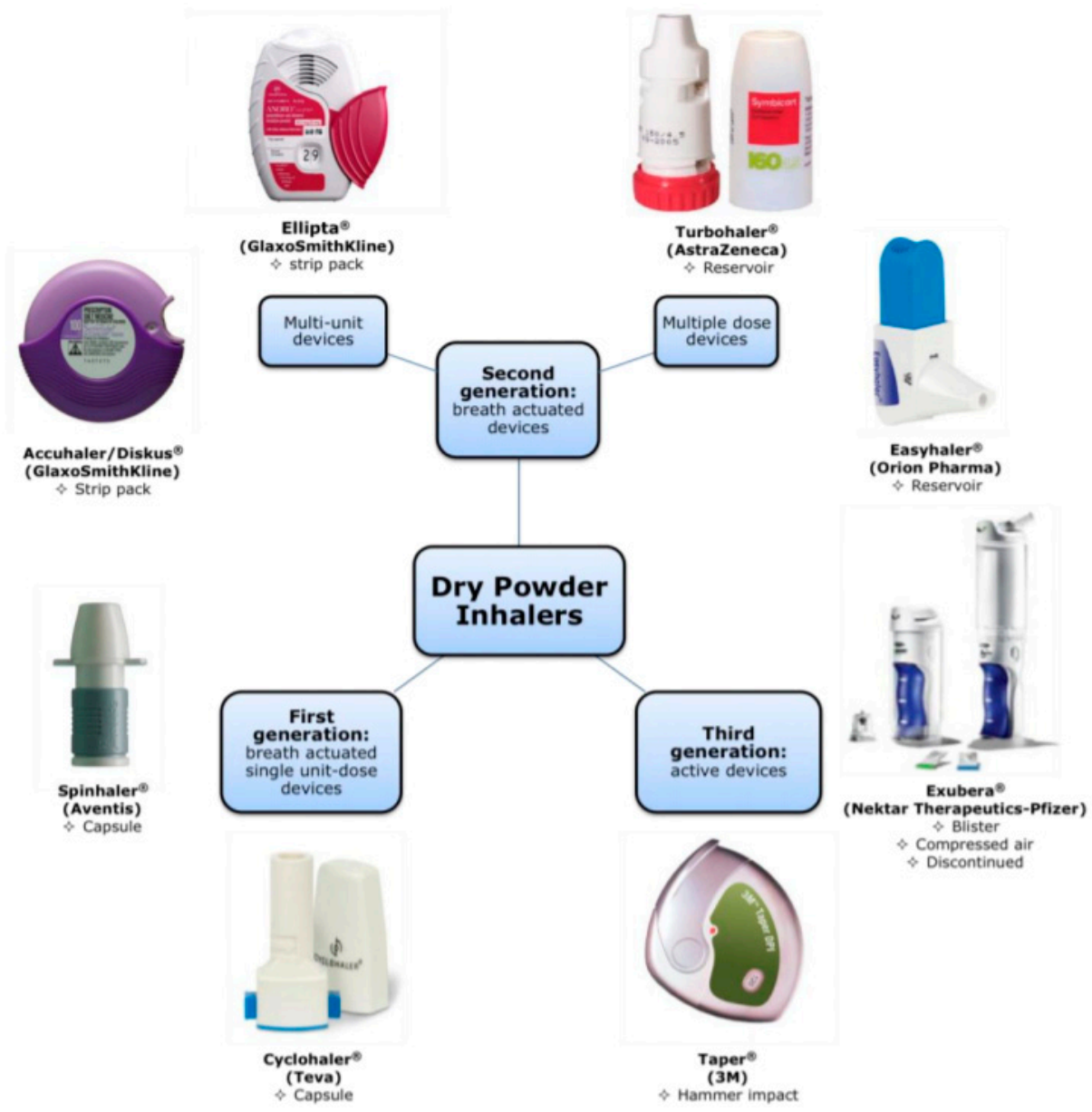

Figure 1. Types of dry powder inhalers (DPIs). Reproduced, with permission, from reference [6].

Several reviews have been published focusing on the deposition of particles in the lungs, the development of DPIs and the formulation strategies used for dry powders for inhalation. Selected reviews published in the last 15 years covering these areas are presented in Table 1. 
Table 1. Selected reviews on pulmonary particle deposition, development and formulations for DPIs published the last 15 years.

\begin{tabular}{|c|c|c|}
\hline Author(s) & Reference & Topics Covered \\
\hline
\end{tabular}

- Mechanisms affecting the transport and deposition of

Darquenne (2012)

[7]

Kourmatzis et al. (2018)

[8]

- $\quad$ Experimental characterisation of extrathoracic airway geometry

- In vitro measurements of airway flow

- Characterisation of inhaler and drug particles

Martin et al. (2018)

- $\quad$ Link between deposition and pharmacokinetic models

Martin et al. (2018)
for predicting lung and systemic exposure to inhaled drugs over time

- Physiological structure and biological functions of the barriers in various regions of the lungs

He et al. (2019)

[10] - Pathogenesis and functional changes of the barrier in obstructive lung disease

- $\quad$ Rational particle design for overcoming lung barriers

\section{Development of DPIs}

Islam and Gladki (2008)

- $\quad$ Factors for consideration in the design of DPIs

- Innovation in the formulation and devices for DPIs

\begin{tabular}{lll}
\hline & & \\
& - & Fundamental mechanisms of drug delivery form DPIs \\
Islam and Clearly (2012) & {$[12] \quad-\quad$ Performance of existing and under development devices } \\
& - & DPIs for systemic delivery \\
& - & Key factors on the development of DPIs
\end{tabular}

Hoppentocht et al.

(2014)
- $\quad$ Misconceptions about optimal DPI use (e.g., pressure drop, device resistance)

- Computational fluid dynamics

- $\quad$ Particle engineering strategies de Boer et al. (2017)

Buttini et al. (2018)

[15]
- $\quad$ DPI design and pulmonary drug deposition and distribution

- Development of DPIs for vaccines and drugs to act systemically
- $\quad$ Applications of Quality by Design within the research field

Levy et al. (2019) to enable prescribing the correct DPI for each patient
}

- Working principles of DPIs and their key characteristics 
Table 1. Cont.

\begin{tabular}{|c|c|c|}
\hline Author(s) & Reference & Topics Covered \\
\hline \multicolumn{3}{|l|}{ Formulations for DPIs } \\
\hline Pilcer and Amighi (2010) & {$[17]$} & $\begin{array}{l}\text { - Use of excipients, their effectiveness and toxicity for } \\
\text { pulmonary administration }\end{array}$ \\
\hline Al-Hallak et al. (2011) & [18] & $\begin{array}{l}\text { - Strategies to formulate nanoparticles (NPs) as DPIs with } \\
\text { enhanced deposition in the deep lungs and } \\
\text { enhanced redispersibility } \\
\text { - In vivo results of using inhalable NPs as DPIs for } \\
\text { therapeutic and diagnostic applications in animal } \\
\text { models are also discussed }\end{array}$ \\
\hline Healy et al. (2014) & [19] & $\begin{array}{l}\text { Approaches to powder formulation and inhaler design } \\
\text { for carrier-free DPIs }\end{array}$ \\
\hline $\begin{array}{l}\text { Gradon and Sosnowski } \\
\text { (2014) }\end{array}$ & [20] & $\begin{array}{l}\text { - } \quad \text { Particle morphology influencing inhalation therapy } \\
\text { - } \quad \text { Production methods of functional particles }\end{array}$ \\
\hline $\begin{array}{l}\text { Brunaugh and Smyth } \\
\text { (2018) }\end{array}$ & {$[21]$} & $\begin{array}{l}\text { Formulation techniques (e.g., hollow particles, particle } \\
\text { surface modification) used to overcome the barriers } \\
\text { associated with the pulmonary delivery of high doses }\end{array}$ \\
\hline Hadiwinoto et al. (2018) & [22] & $\begin{array}{l}\text { - Particle engineering techniques (e.g., direct control } \\
\text { crystallisation, spray drying, spray freeze drying, } \\
\text { micronisation) used for the manufacture of drugs } \\
\text { for DPIs }\end{array}$ \\
\hline
\end{tabular}

\section{Formulations for DPIs Based on Nanoparticle Engineering}

Drug particles should exhibit an aerodynamic diameter (MMAD) smaller than $10 \mu \mathrm{m}$. MMAD about $2-6 \mu \mathrm{m}$ is required for topical delivery and $\sim 1-3 \mu \mathrm{m}$ for targeting deposition to the small airways. Such fine drug particles exhibit a high surface free energy imparting high cohesiveness and adhesivity to the powder. They also suffer from poor flowability and aerosolisation performance as they are retained in the device when used alone.

The most common approach for a DPI formulation is to blend fine drug particles with an inert carrier (most usually lactose) consisting of coarser particles. During blending the fine drug particles adhere to the surfaces of the carrier particles forming adhesive mixtures $[23,24]$. The dispersion of drug particles from the adhesive mixtures upon inhalation is a three-step process including (i) fluidisation of the powder in the airstream, (ii) detachment of primary and agglomerated drug particles and (iii) break-up of agglomerates into primary particles [25].

Over the last three decades, particle engineering for pulmonary drug delivery of carrier-free particles has evolved. Besides avoiding problems associated with the presence of carrier (e.g., blend uniformity), these particles also make possible the delivery of high drug payloads to the lungs, which is particularly useful for the administration of antibiotics [19]. However, it should be stated that due to the absence of a carrier these formulations may result in more aggregation and thus may suffer from reduced emitted doses.

The most widely known type of carrier-free particles are the spheroids (i.e., soft agglomerates of micronised particles). They are used with the Turbohaler ${ }^{\circledR}$ (AstraZeneca) which breaks them into 
individual particles upon inhalation. The spheroids have a diameter of about $0.5 \mathrm{~mm}$ and thus exhibit enhanced flowability compared to micronised particles and do not suffer from electrostatic charging during handling and operation.

\subsection{Nanoparticles in Pulmonary Drug Delivery}

As per the US FDA, materials are classified as being in the nanoscale if they have at least one dimension in the size range of $1-100 \mathrm{~nm}$. The upper limit of $100 \mathrm{~nm}$ is considered constraining and according to a more expanded and inclusive definition, particles below $1000 \mathrm{~nm}$ in all each dimension (i.e., sub-micron particles) can be designated as nanoparticles (NPs) [26]. The latter definition is applicable in the pharmaceutical field, since important material and powder properties such as aggregation, dissolution and solubility begin to alter once the size of the particles is reduced to the sub-micron level, due to the increased cohesiveness [27], surface area to volume ratio [28] and curvature [29].

The use of NPs has gained momentum in drug delivery with research on NP-based drug delivery systems expanding in recent years. NP-based formulations are considered one of the most prevalent strategies to address low solubility in drug development and thus increase bioavailability of poorly water-soluble drugs. Due to their reduced particle size, NPs have an increased surface area available for solvation and exhibit increased dissolution rate for solid drugs. NPs may also exhibit higher solubility compared to microparticles due to enhanced particle curvature and introduction of defects in the crystal lattice. A detailed overview of the effect of particle size reduction on dissolution rates, saturation solubility and in vivo performance of drug NPs has been provided by Williams et al. (2013) [30]. Also, by suspending the drug as NPs, a higher dose can be achieved compared to a solution where the dose is limited by the solubility of the drug. Different types of nanotherapeutics have been applied in drug delivery, such as: nanocomplexes, nanoemulsions, polymeric micelles, liposomes, virosomes, polymeric nanoparticles and nanocrystals (Figure 2).

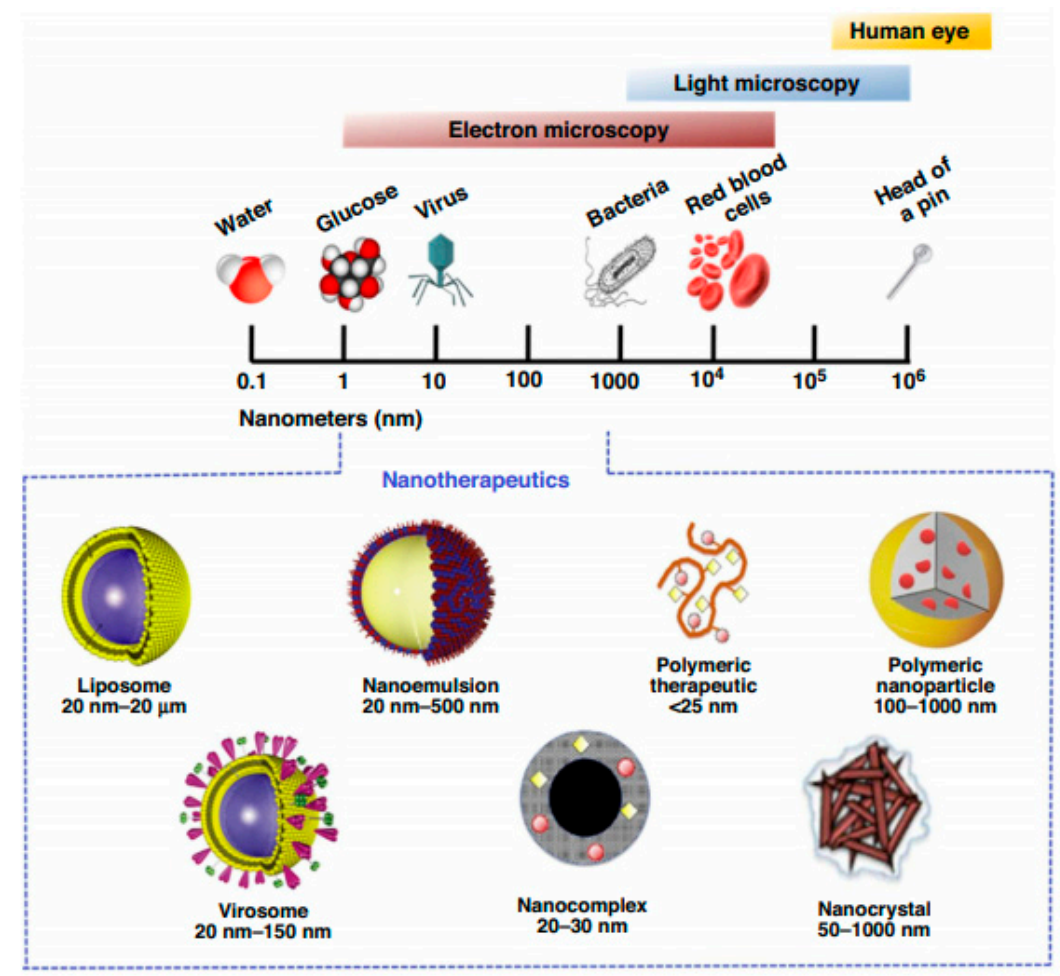

Figure 2. Nanoscale comparison and types of nanotherapeutics used in drug delivery. Reproduced, with permission, from reference [31]. 
The advantages of NPs stated previously can be extended to the pulmonary route of administration. According to Iyer et al. (2015), NP-based therapeutics can assist in the following aspects of pulmonary drug delivery: (i) Achieve therapeutic effects in the lungs at lower doses compared to oral delivery, (ii) enhance delivery of poorly water-soluble drugs, (iii) protect drugs against degradation, (iv) achieve targeted and controlled drug delivery, (v) protect therapeutic agents against mucociliary clearance and vi) enhance NP internalisation [32].

Regarding drug absorption and local bioavailability following delivery to the lungs, they will depend upon the fraction of deposited drug that dissolves in the lungs. Drugs with low dissolution rate may be removed from the lung via mucociliary clearance before absorption resulting in reduced local bioavailability. NP-based formulations have been found to promote faster absorption following inhalation of poorly water-soluble drugs that have dissolution-limited absorption (e.g., beclometasone dipropionate, budesonide, itraconazole) [33].

\subsection{Nanoparticle-Based Dry Powders for Inhalation}

Formation of NPs usually takes place in a liquid medium as a nanosuspension (colloidal system). Liquid nanosuspensions are associated with physical instability including sedimentation, creaming, crystal growth (also known as Ostwald ripening), aggregation and solid state transformation [34]. Due to these issues, it is difficult to ensure that the particle size of the nanosuspension will not change upon storage. On the other hand, solid dosage forms exhibit enhanced physical and chemical stability.

As stated in the beginning of this review, optimal lung deposition can be achieved with two distinct particle sizes; $1-5 \mu \mathrm{m}$ and smaller than $50 \mathrm{~nm}$ [4]. This is because when NPs greater than 50 $\mathrm{nm}$ are delivered to the lungs there is high probability of exhalation prior to deposition [35]. Moreover, NPs tend to strongly aggregate upon aerosolisation under the normal airflow rates in passive DPIs and their cohesive nature makes their handling extremely difficult [36]. To overcome these limitations, the controlled agglomeration of NPs to micron-sized clusters has been proposed as "an approach to harmonise the advantages of nanoparticles with the aerodynamics of small microparticles so as to achieve an improved bioavailability and aerosolisation behaviour of the drug" [37]. Thus, solidification of nanosuspensions to inhalable NP agglomerates of $1-5 \mu \mathrm{m}$ can be used as strategy for the effective administration of NPs to the lungs using DPIs.

As reported by Muralidharan et al. (2015), conversion of NPs to inhalation powders comes with the following challenges: (i) maintain the particle size in the dry state, (ii) prevent aggregation of NPs in the inhaler, (iii) achieve efficient redispersion of the NP agglomerates in the lung fluid and (iv) preserve the biological activity of the therapeutic agent (especially biotherapeutics) throughout the processing steps [38]. Entrapping the NPs in a matrix of excipients (e.g., water-soluble sugar-based compounds) can be used as an approach to form micron-sized particles of NPs embedded in matrix formers. These micron-sized composite particles act as an intermediate delivery system during storage and administration until they reach the pulmonary mucus lining where the highly soluble matrix formers dissolve, releasing the NPs.

Various particle engineering techniques such as spray drying, freeze drying, spray-freeze drying and aerosol flow reactor have been used to produce NP agglomerates (Figure 3) [39,40]). The next sections of this review focus on the use of spray drying for the formation of NP-based powders for inhalation. 


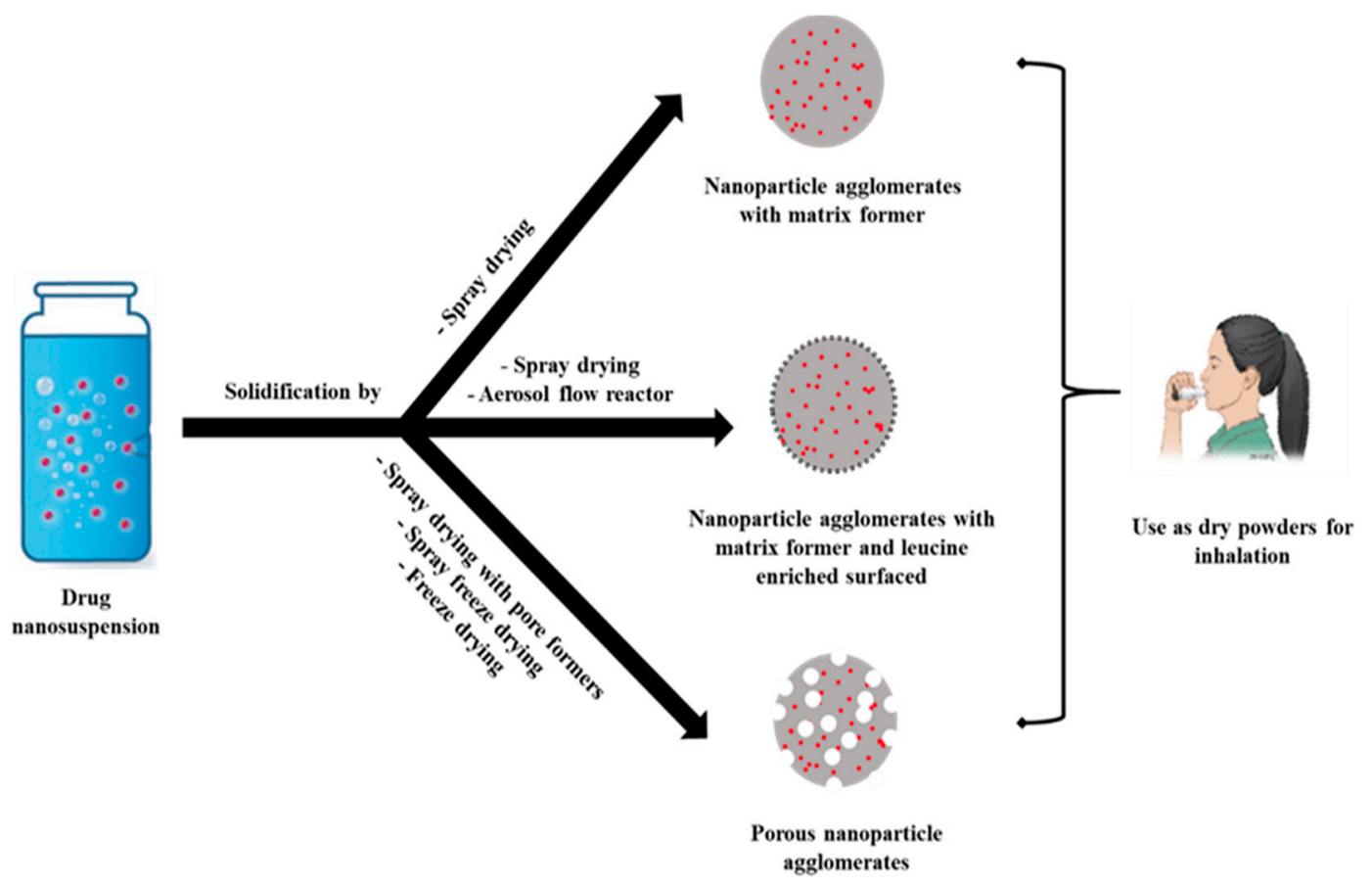

Figure 3. Schematic representation of the various solidification approaches for the preparation of inhalable micron-sized NP agglomerates. Adapted from reference [39].

\section{Particle Engineering Using Spray Drying}

Spray drying is a well-established technique with a long history of use in a variety of fields (e.g., foods and chemicals). The use of spray drying for the pharmaceutical industry dates to the early 20th century when it was used for the drying of blood. Since then, it has been employed for various pharmaceutical applications including formation of amorphous solid dispersions, encapsulation of drugs and essential oils in excipient matrices, and spray drying of biopharmaceuticals (e.g., proteins, vaccines, Deoxyribonucleic Acid (DNA), antibodies) [41,42].

Spray drying is widely applied to produce pharmaceutical powders with particle size ranging from the nanometre to the micrometre scale (Figure 4). It has been extensively used for the production of inhalation particles as it allows manipulation and control of properties such as particle size distribution, shape, density, flowability, moisture content, crystallinity and dispersibility of the powders [43]. Additionally, spray drying can be used both as a particle-engineering and as a crystal-engineering platform.

Spray drying is a single-step manufacturing process where a liquid feed is converted to a dried particulate form. The main principles behind the process are the atomisation of liquid feed into fine droplets and the evaporation of the solvent by means of a hot drying gas. The process follows four steps: liquid feedstock preparation, atomisation of the feed into a spray through a nozzle and contact with the hot drying gas, particle formation by evaporative mass transfer of the liquid from the droplet into the drying gas and lastly, separation of the dried product from the gas [44]. 


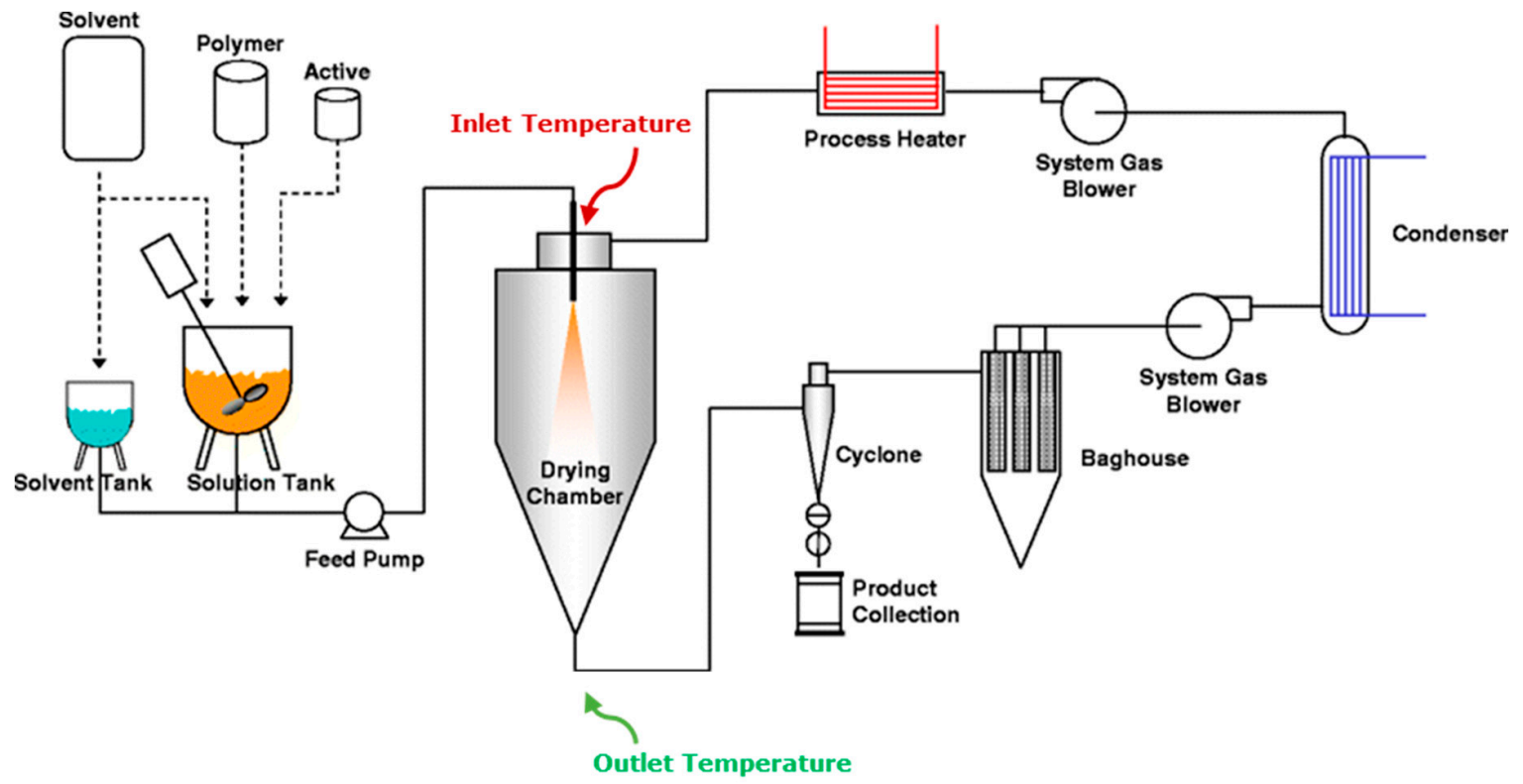

Figure 4. Schematic representation of spray dryer instrumentation. Reproduced, with permission, from reference [45].

\subsection{Liquid Feedstock Preparation}

The liquid feed should be of suitable viscosity to be pumpable. It can be a solution, suspension or emulsion made up from the active substance(s), excipient(s), a solvent or a mixture of solvents. The qualitative and quantitative composition of the feedstock is selected considering the target product characteristics and the solubility of the active substance. In the case of emulsions and suspensions, the stability of the liquid feed plays an important role as it is associated with the homogeneity of the spray-dried product but also may lead to dryer operational issues (e.g., nozzle blockage).

For efficient spray drying of colloidal systems, the size of the dispersed phase should be smaller than the nozzle orifice to avoid clogging. Increase of solids concentration in the liquid feed has been reported to lead to formation of larger particles and increased effective particle density (including both open and closed pores) [46]. For example, Cheow et al. (2010), reported that spray drying silica NPs at low $\mathrm{pH}(<7)$ and low feed concentration $(<1 \% w / w)$ generally resulted in particles with small geometric and aerodynamic diameters $(\sim 3 \mu \mathrm{m})$ with monodisperse size distribution while spray drying of higher feed concentrations led to increased particle size and multimodal size distribution [47].

\subsection{Atomisation}

In this step, the liquid feed is broken up into a collection of droplets with the use of a nozzle. Different types of atomizers are available in spray dryers for development (two-fluid or pneumatic, hydraulic pressure, rotary disk atomizer and ultrasonic nozzles) but also commercial pharmaceutical applications. The two-fluid nozzles are commonly used in the pharmaceutical industry for the preparation of respirable particles. This is due to their suitability for smaller scale plants and the formation of smaller size droplets compared to other types of atomizers. During the process, atomisation occurs by rapid expansion of the supplied gas, mixed with the liquid feed either inside the nozzle body (internal mixing), or at its tip (external mixing). The velocity of the gas is much higher than that of the liquid at the orifice and provides the work required to create the large surface area of the spray. A detailed study on spray drying and atomisation using a two-fluid nozzle for the production of inhalable particles has been provided by Kemp et al. (2013) [48]. 


\subsection{Drying}

The drying of the droplets is the step of solvent removal, which is described as a coupled heat and mass transfer phenomenon, with the difference between the vapour pressure of the solvent in the droplet and its partial pressure in the gas phase being the driving force. The drying kinetics of droplets containing suspended particles, such as NPs, can be divided into two stages. The first known as constant-rate period comprises the solvent evaporation from the droplet surface resulting in a constant rate of diameter decrease. The second stage, known as falling-rate period starts at the critical moisture content, when the solvent from the droplet interior cannot keep the entire surface saturated and thus a shell is formed by deposition of particles at the liquid-air interface. During this stage, evaporation continues through the pores of the shell until the point of equilibrium moisture content is reached, signifying the end of drying (Figure 5) [49,50].

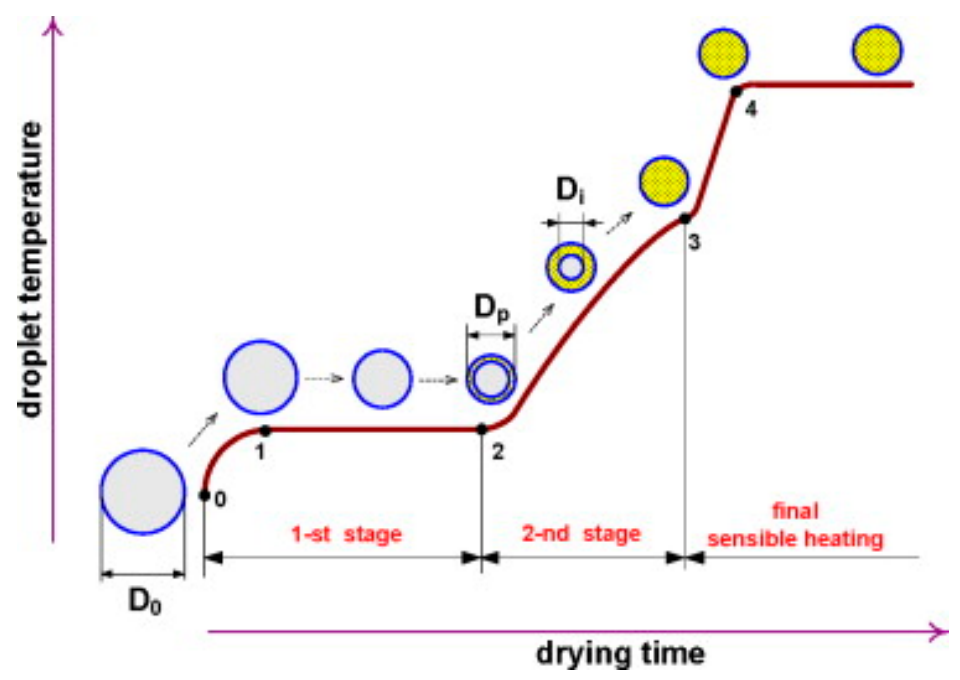

Figure 5. Drying kinetics of droplet temperature. The time interval between 0 and 1 corresponds to droplet initial heating, period 1-2 to droplet evaporation period, period 2-3 to second drying stage and period 3-4 to particle heating up to equilibrium with the surrounding drying agent $\left(\mathrm{D}_{0}\right.$ : initial diameter, Dp: particle diameter, Di: internal diameter). Reproduced, with permission from reference [49].

Particle formation by spray drying can be described by two dimensionless parameters; the Peclet number $(\mathrm{Pe})$ and the initial saturation of excipients. Pe represents the rate of liquid evaporation from the drying droplet relative to the diffusion rate of dispersed phase to the centre of the droplet, (Equation (1)) [51].

$$
\mathrm{Pe}=\mathrm{R}^{2} / \tau_{d} \mathrm{D}
$$

$\mathrm{R}$ is the droplet radius, $\mathrm{D}$ the solute or NP diffusion coefficient and $\tau_{d}$ the drying time of the droplet. High Pe number signifies accumulation of dispersed phase at the surface and shrinkage. From Equation (1), it appears that drying factors such as drying temperature and type of solvent that affect evaporation and drying time, as well as particle size and solubility of dispersed phase that affect diffusivity are expected to control Pe. For low Pe numbers (i.e., Pe $\ll 1$ ) diffusion of the particles is faster or of the same order compared to the radial velocity of the receding droplet surface. This means that the particles will remain evenly distributed in the droplet during evaporation, resulting in spherical particle agglomerates. For high Pe numbers (i.e., Pe $\gg 1$ ), the particles have insufficient time to diffuse and therefore accumulate in the liquid-air interface. As evaporation continues through the crust, hollow or doughnut shape particles are formed (Figure 6) [43,52]. Viscoelastic material behaviour leads to the formation of a flexible surface skin in the late stages of drying, causing localised collapse and surface cavities [53]. The morphology of the spray-dried particles was found to depend on the size and concentration of the suspended particles as well as the initial droplet volume. Osman et al. (2017) 
reported that suspensions containing NPs exhibit low Pe due to higher diffusion rate and upon drying they form a spherical shell with irregular surfaces resulting in spherical aggregates/grains [50]. Conversely, suspensions containing microparticles with high Pe number, upon drying, tend to form a surface crust that collapses at the late drying stages resulting in particles with half apricot-like shape.

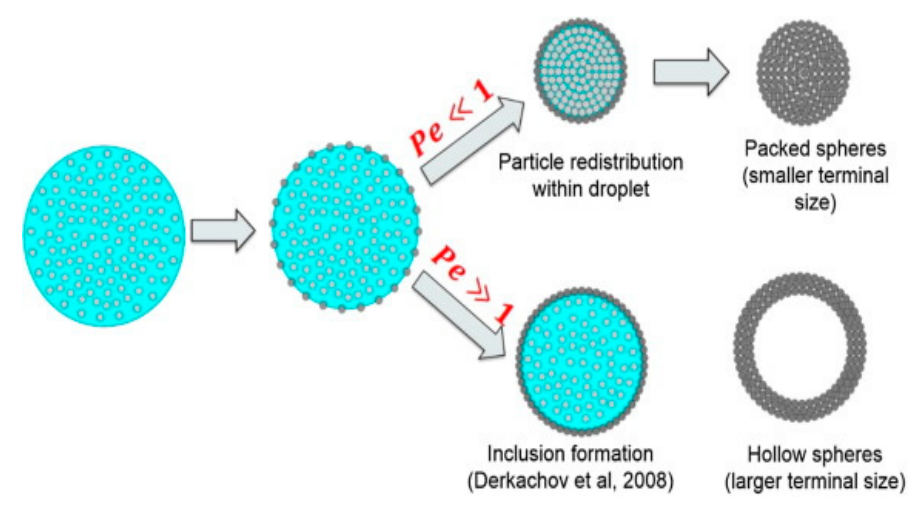

Figure 6. Drying of droplets containing particles of low (upper) and high (lower) Peclet number. Reproduced, with permission, from reference [52].

\subsection{Separation}

The separation of the dried particles from the drying gas is the final step of the process. Although the primary separation of the dried particles from the drying gas takes place at the base of the drying chamber, use of cyclones is the most commonly applied separation technique for the recovery of the finer particles from the drying gas. In the cyclone, centrifugal forces are applied to particles, which are collected in a bottom vessel. Standard cyclones have a low efficiency for collecting spray-dried particles smaller than $2 \mu \mathrm{m}$. The cyclone's poor efficiency in collecting fine particles together with loss of material in other parts of the spray dryer (e.g., by adhesion to the walls of the drying chamber) leads to low production yield. This can be particularly disadvantageous for the spray drying of high-valued biopharmaceuticals as it increases the production cost [54].

The design and relative dimensions of the cyclone influence product recovery. The use of "improved" cyclones has been found to enhance collection efficiency (Figure 7). Use of an "improved", narrow cyclone was found to increase the production yield of spray-dried amorphous trehalose [55]. Production of inhalable particles by spray drying using the Buchi B-290 equipped with the standard cyclone resulted in product recovery of around 13\% while when the same material was spray dried using the high-efficiency cyclone typical product yields of 50-70\% were achieved [56].

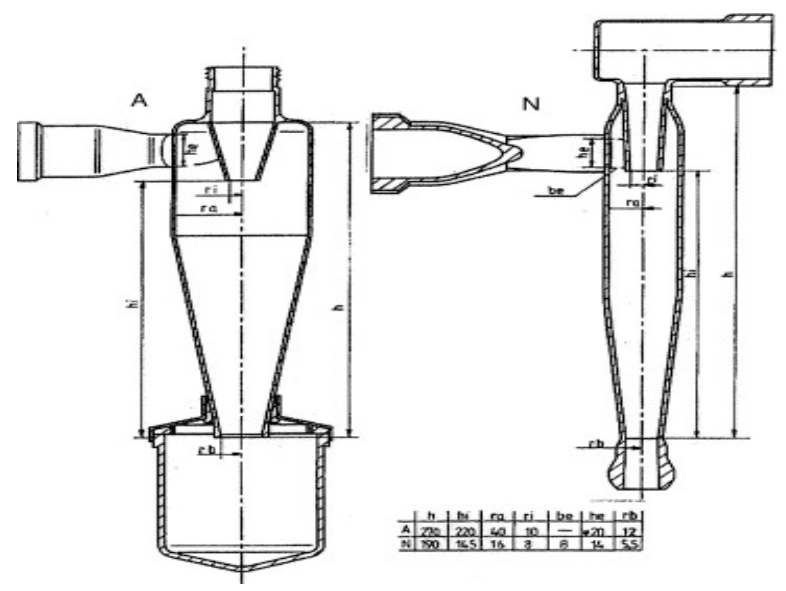

Figure 7. Design of a standard Buchi cyclone (left) and an improved cyclone (right). Reproduced, with permission, from reference [55]. 
This review will present the production and therapeutic applications of various types of NP-based dry powder formulations produced by conventional and alternative spray drying techniques.

\section{Studies on Inhalable Nanoparticle-Based Drug Formulations Produced by Spray Drying}

\subsection{Nanoporous Microparticles (NPMPs)}

Porous particles for inhalation offer a particle engineering solution to improve deposition to the lung. Large porous particles with low mass density and large size, such that the particles' aerodynamic diameter fits into the range of 1 to $3 \mu \mathrm{m}$, were found to exhibit improved aerosolisation performance compared to non-porous particles, which was attributed to their lower tendency for aggregation [57].

Nanoporous microparticles (NPMPs) were introduced by Healy et al. (2008), who reported on the use of spray drying for the production of excipient-free porous microparticles [58]. The process involves spray drying the solute (excipient, drug or both) from a mixed/solvent antisolvent system. Ammonium carbonate has been used as a pore former for the formation of inhalable NPMPs [59]. Detailed discussion on the proposed mechanism behind the formation of the NPMPs has been provided by Healy et al. (2014) and Paluch et al. (2012) [19,60].

Ní Ógáin et al. (2011) studied the use of spray drying for the production of raffinose and trehalose NPMPs for inhalation [61]. NPMPs spray dried from an 80:20 (v/v) methanol and n-butyl acetate mixed solvent resulted in amorphous NPMPs with sufficiently high glass transitions temperatures (i.e., $\mathrm{Tg}$ $\sim 124{ }^{\circ} \mathrm{C}$ and $120^{\circ} \mathrm{C}$ for trehalose and raffinose, respectively). Thus, these NPMPs were considered to exhibit good physical stability at room temperature and good potential to act as protein carriers and stabilisers. A 1:4 sugar to protein weight ratio resulted in successful incorporation of the model protein, lysozyme into the NPMPs. Hence, these systems can be potentially used as carriers for peptide or protein drug delivery via the pulmonary route. In a follow up study, Ní Ógáin et al. (2012) highlighted the importance of the composition of the mixed solvent on the production of protein/peptide NPMPs and extended the application of the method to water-soluble proteins such as trypsin [62]. Inclusion of water was deemed necessary for the production of NPMPs of trypsin with excipients such as trehalose, raffinose and hydroxypropyl- $\beta$-cyclodextrin. Trypsin in the NPMPs was found to retain its biological activity in all cases. This was attributed to the fact that the protein is exposed to lower thermal stress when spray dried from organic rather than aqueous systems. The NPMPs achieved fine particle fractions (FPFs) around $45 \%$ and were found stable upon storage under conditions of low relative humidity at either $4{ }^{\circ} \mathrm{C}$ or $25^{\circ} \mathrm{C}$

Amaro et al. (2011) investigated the effect of operating parameters of a Büchi Mini Spray Dryer B-290 on the characteristics of trehalose and raffinose powders intended for use as carriers of biomolecules for inhalation [63]. These sugars were spray dried from 80:20 (v/v) methanol:n-butyl acetate solutions. Experimental conditions were optimized by applying experimental design. The most significant factor affecting production yield, particle size and specific surface area was the gas flow. Production yield was affected by both the gas flow and the pump speed while the amount of residual solvent was affected by the inlet temperature. Raffinose NPMPs exhibited higher FPFs in in vitro aerosolisation testing using the Andersen cascade impactor (ACI) compared to the trehalose NPMPs. This was attributed to the larger surface area of the raffinose NPMPs compared to the trehalose NPMPs. Thus, it was concluded that raffinose NPMPs are the formulation of choice for a dry powder inhalation. The suitability of raffinose as a non-reducing sugar for the production of NPMPs containing biomolecules was also demonstrated in a later study focusing on the aerodynamic and pharmacokinetic characteristics of NPMPs for the pulmonary delivery of the therapeutic peptide, salmon calcitonin [64]. The NPMPs exhibited a bioavailability between 10.1 and $14.9 \%$ and a similar pharmacokinetic profile to that of salmon calcitonin in solution. These findings indicate the advantages of these dry powder formulations as non-invasive delivery systems offering ease of administration of salmon calcitonin and potentially other peptides/proteins. 
Apart from biomolecules, the concept of NPMPs has been applied for the production of inhalable dry powders of small molecular weight drugs. Nolan et al. (2011) examined the feasibility of producing NPMPs of the hydrophilic drug sodium cromoglicate which is used in the treatment of asthma by adapting a spray-drying process initially used for hydrophobic drugs (Figure 8) [65]. The ACI and the twin-stage impinger (TSI) were used to determine the physicochemical properties and in vitro deposition of the spray-dried particles and compare them with the marketed product Intal ${ }^{\circledR}$ (Sanofi) which contains the active substance in micronised form. The produced NPMPs displayed enhanced in vitro drug deposition compared to the marketed product, following aersolisation through the ACI using the Spinhaler ${ }^{\circledR}$ device. For both the NPMPs and the marketed product, particle morphology was altered upon storage at $25^{\circ} \mathrm{C} / 60 \% \mathrm{RH}$ and the in vitro deposition performance deteriorated. However, the morphology and aerosolisation performance of the NPMPs was found to be retained upon storage under dry conditions (i.e., in the presence of dessicant).
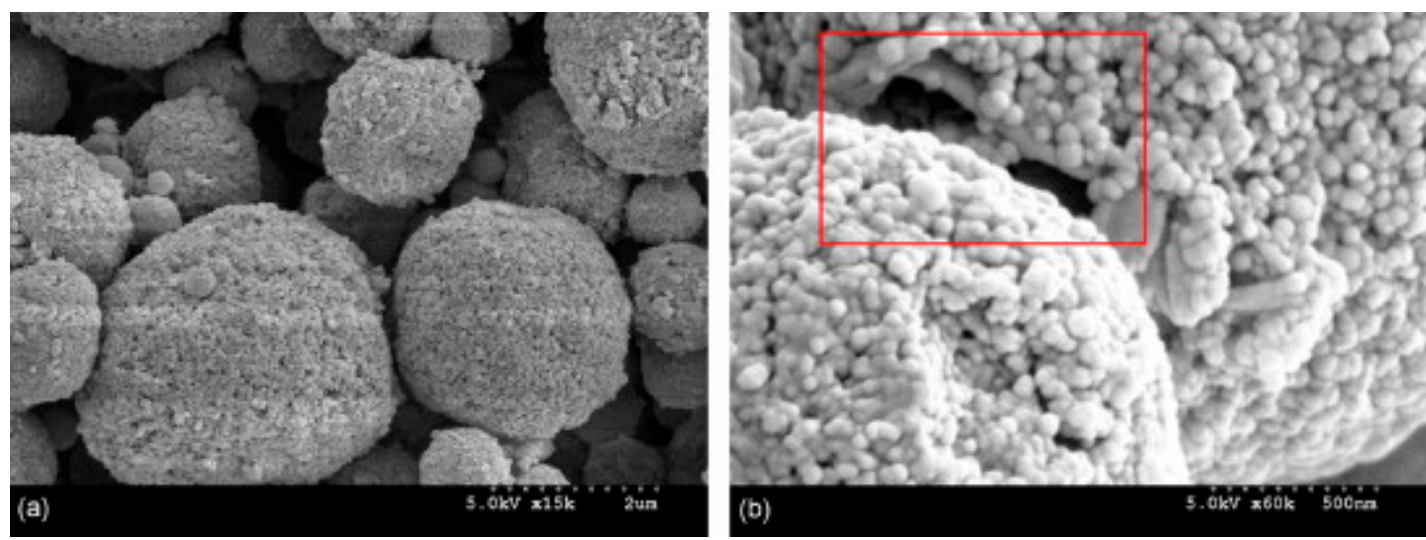

Figure 8. Scanning electron microscopy images of spray-dried sodium cromoglicate nanoporous microparticles (NPMPs). (a): $2 \mu \mathrm{m}$, magnification: $15 \mathrm{k}$; (b): $500 \mathrm{~nm}$, magnification: $60 \mathrm{k}$. Reproduced, with permission, from reference [65].

Gad et al. (2012) investigated the impact of ammonium carbonate as a pore former on the characteristics of the anti-tubercular agent, p-aminosalicylic acid and its ammonium salt, spray dried from ethanol/water solvent systems [66]. The morphological, aerodynamic and physicochemical properties of the nano-structured microparticles were examined and evaluated along with their solid state. The spray-dried particles showed potential for pulmonary delivery as they demonstrated higher emitted dose in in vitro deposition studies using the TSI compared to the micronised drug. Under appropriate processing conditions, ammonium carbonate interacted with p-aminosalicylic acid resulting in the formation of a novel solid state form.

To overcome problems such as viscous mucus which are often encountered in patients with respiratory diseases but also to increase budesonide diffusion within lung fluid, Tewes et al. (2013) developed a combinatory NPMPs system of budesonide with the mucolytic drug ambroxol hydrochloride, to be inhaled as a dry powder [67]. The combinatory particles were formulated by co-spray drying and were characterised by various physicochemical methods. NPMPs formulated in the presence of ammonium carbonate had superior aerodynamic properties due to the neutralisation of ambroxol hydrochloride and the subsequent formation of ambroxol base. In this way, ambroxol base could behave similarly to budesonide and prompt nanoprecipitation when spray dried from an ethanol/water mixture. Based on the excellent aerosolisation performance and the improved permeability of budesonide across mucus when tested in vitro, it was concluded that the combinatory NPMPs containing a mucolytic agent could be used as a strategy to increase diffusion of drugs including antibiotics to the lungs for the treatment of diseases where abnormally viscous mucus develops (e.g., cystic fibrosis). 
The results of the aforementioned studies indicate that formation of NPMPs can be used as a particle-engineering strategy for production of inhalable dry powders of both biomolecules and small molecular weight drugs using spray drying and non-reducing sugars as excipients and ammonium carbonate as pore former.

\subsection{Nanocrystalline Agglomerates}

Controlled agglomeration of nanoparticles to micrometre-sized composites combines the advantages of NPs with the aerodynamics of microparticles. This section will mainly focus on the solidification of drug nanocrystals by spray drying to form inhalable micron-sized structures composed of nanoparticles usually referred to as nanocrystalline agglomerates.

Production of nanosuspensions by either top-down (e.g., wet milling, high-pressure homogenisation) or bottom-up methods (e.g., solvent/antisolvent precipitation) followed by spray drying as the solidification step has been applied for the production of inhalable nanocrystalline agglomerates of various drugs [39]. Specifically, this combined particle-engineering approach has been used for the production of inhalable nanocrystalline agglomerates of drugs such as cyclosporine A [68], itraconazole [69], meloxicam [70], indometacin [71], theophylline [72], ibuprofen [73], resveratrol [74], tadalafil [75] and budesonide [76]. Nanocrystalline agglomerates containing drug combinations have also been reported for tobramycin/clarithromycin [77] and budesonide/theophylline [78].

By using high-pressure homogenisation followed by spray drying, Pilcer et al. (2013) developed easily dispersible, porous nanocrystalline agglomerates of tobramycin surrounded by a matrix of amorphous clarithromycin [77]. The dissolution profiles showed that both drugs tend to dissolve without any difficulties in the lung. The fine particle fractions (FPFs) determined using the next generation impactor (NGI) were found to increase from 35\% and 31\% for the physical blend of tobramycin and clarithromycin, respectively, to $63 \%$ and $62 \%$ for the nanocrystalline agglomerates. Local drug deposition profiles were similar for the two antibiotics, allowing them to reach the target simultaneously. The combined nanocrystalline agglomerates could be considered as attractive formulations for the local therapy of lung infections, as high drug loads can be targeted to the site of infection minimising the side effects associated with the systemic administration of antibiotics.

Inclusion of excipients such as mannitol (matrix former) and leucine (surface-active aerosolisation enhancer) to the nanosuspensions prior to the spray-drying step has been reported as a way to improve the redispersibility of the nanocrystalline agglomerates and enhance their aerosolisation performance [68,71]. Specifically, in the study of Malamatari et al. (2015), nanocrystals of indometacin were prepared and assembled to NP-agglomerates with and without matrix formers (mannitol and l-leucine) by coupling wet milling and spray drying (Figure 9) [71]. The nanocrystalline agglomerates exhibited enhanced dissolution compared to physical mixtures of drug and stabilisers, while incorporation of matrix formers enabled redispersibility upon hydration, increased drug dissolution and improved significantly their in vitro aerosolisation. In a follow up study using the low melting point and ductile drug ibuprofen, Malamatari et al. (2017) applied experimental design to gain insight into the formation of inhalable nanocrystalline agglomerates using wet milling followed by spray drying [73]. Leucine to drug ratio, mannitol to drug ratio and the type of stabiliser were found to be significant factors on the overall yield of the process. Mannitol to drug ratio was found to be a critical parameter influencing redispersibility while both mannitol to drug ratio and leucine to drug ratio were found to influence the aerosolisation performance of nanocrystalline agglomerates. The results on the role of mannitol on the dispersibility of the NP agglomerates are corroborated by the study of Torge et al. (2017) where the use of a water-soluble excipient such as mannitol was found to be necessary to enable the release of poly(lactic-co-glycolic acid) NPs from microparticles when tested in a simplified in vitro model simulating conditions similar to the lungs [53]. 
(a)
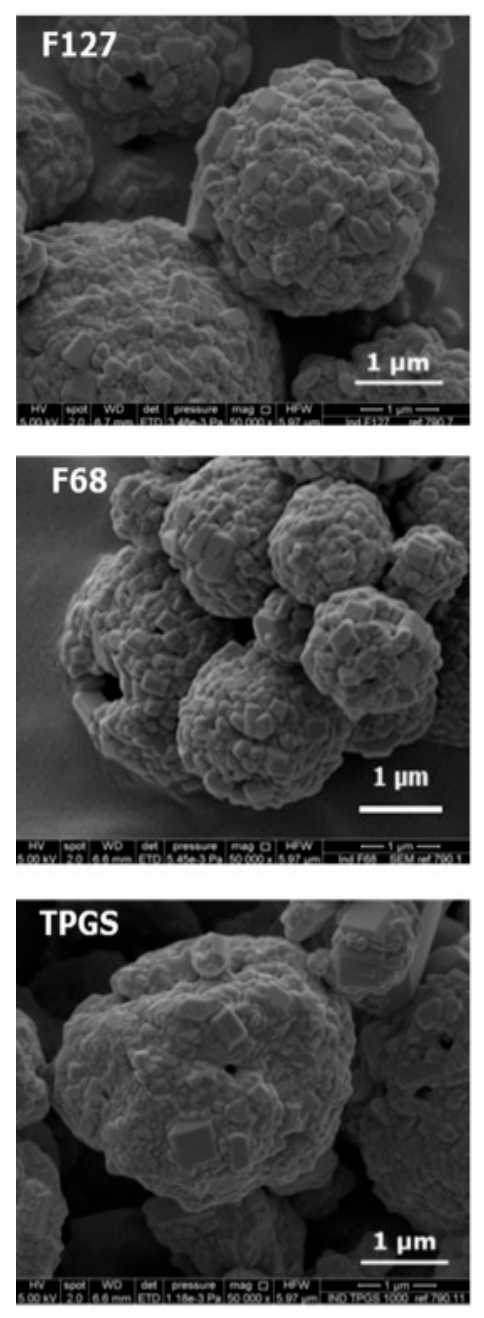

(b)
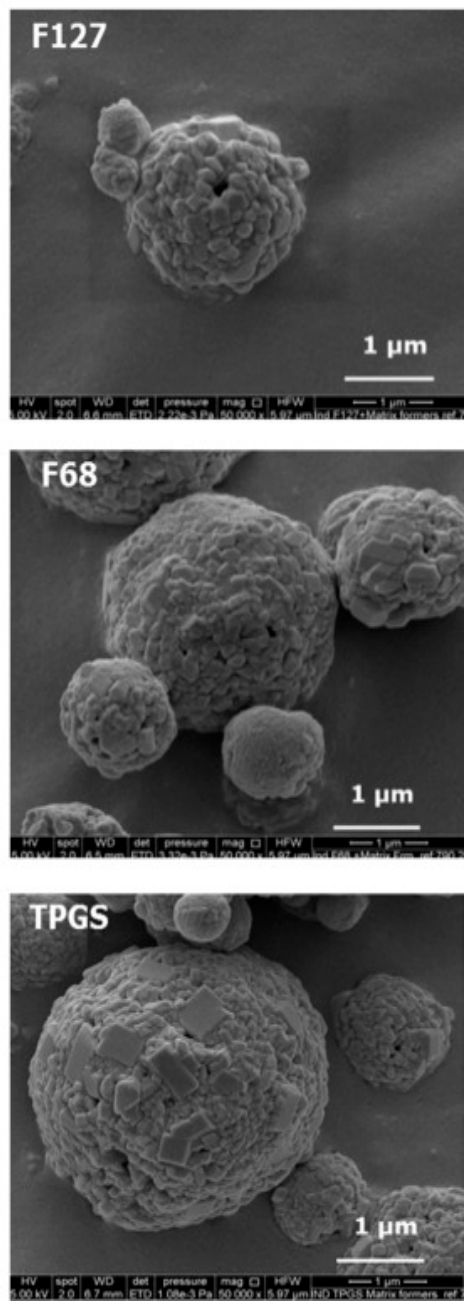

Figure 9. Scanning electron microscopy images of indomethacin nanocrystalline agglomerates: (a) Without and (b) with matrix formers prepared with different stabilisers (10\% w/w of IND). Reproduced, with permission, from reference [71].

Teymouri Rad et al. (2019) prepared inhalable tadalafil nanocrystalline agglomerates as a dry powder formulation by spray drying for increasing bioavailability and treatment efficacy of pulmonary arterial hypertension [75]. D-optimal experimental design was used to optimise formulation parameters, namely nanocrystal to sugar ratio, L-isoleucine to sugar ratio and sugar type. The physicochemical characteristics of the powders were investigated and the pharmacokinetic parameters after intratracheal insufflation to Wistar rats were evaluated from plasma and lung tissue findings, and were compared with a control group receiving a marketed product of tadalafil by oral administration. The results of the study showed that pulmonary administration of tadalafil formulated as nanocrystalline agglomerates achieved rapid onset of action, higher local drug concentration and longer drug retention in the lungs compared to the conventional oral administration. It was concluded that inhalable tadalafil nanocrystalline agglomerates could be introduced as an alternative to oral tadalafil in the treatment of pulmonary arterial hypertension.

Modifications to the coupled process have extended the application of nanocrystalline agglomerates to water-soluble drugs but also drug combinations. Specifically, Malamatari et al. (2016) by using theophylline, as a water-soluble drug, demonstrated successful adaptation of wet co-milling with mannitol in an organic solvent followed by spray drying as a method for producing respirable particles of water-soluble drugs or drugs that are prone to crystal transformation (i.e., hydrates) [72]. Moreover, 
Leng et al. (2018) investigated the advantages and disadvantages of two-fluid and three-fluid spray drying nozzles on the formulation of inhalable nanocrystalline agglomerates [79]. Agglomerates obtained by spray drying a nanosuspension of budesonide containing mannitol using a two-fluid nozzle were superior to the amorphous solid dispersion dry powders obtained by spray drying budesonide and mannitol from solution using a three-fluid spray nozzle regarding production yield, homogeneity of drug content and aerodynamic performance. In a follow up study, a comparison between a two-fluid and three-fluid nozzle was also performed regarding formation of inhalable combination particles of budesonide and theophylline [78]. The powder prepared by spray drying suspension using the two-fluid nozzle gave the best formulation in terms of physical stability, crystallinity, dissolution and co-deposition profile compared to powders prepared from solutions or suspensions of both drugs using the three-fluid nozzle.

The aforementioned studies demonstrate the wide applicability of spray drying in the formation of nanocrystalline agglomerates of various drugs in the formulation of various therapeutic agents for pulmonary delivery aimed at local or systemic action. The versatility of their application lies in the ability to finetune several processes (e.g., type of nozzle) and formulation parameters (e.g., stabiliser or matrix former) and in this way making the coupled process suitable for drugs with different physicochemical characteristics.

\subsection{Proliposomes, Solid Lipid Nanoparticles and Nanocrystal Liposomal Powders}

The use of lipid-based delivery systems for pulmonary drug delivery to the lungs may enhance drug retention in the lungs leading to improved therapeutic efficacy but also safety through reduction of extra-pulmonary side effects [80]. Lipid-based pulmonary drug delivery systems include microemulsions, nanoemulsions, solid lipid nanoparticles, liposomes and micelles. A review on lipid-based pulmonary delivery systems has been provided by Ngan and Asmawi (2018) [81].

Liposomes are a family of vesicular structures based on lipid bilayers surrounding aqueous compartments [82]. Conventional liposomes composed of phospholipids and/or cholesterol have the unique ability to entrap both lipophilic (into the bilayer membrane) and hydrophilic compounds (in the aqueous interior). Despite their advantages, liposomes in aqueous systems suffer from physical instability upon storage (e.g., hydrolysis, oxidation, sedimentation and aggregation). Instead, proliposomes are dry free-flowing powders which can hydrate immediately and form liposomes through contact with water or biological fluids [83]. Proliposomes overcome the instability issues of liposomes and can act as liposome precursors which upon hydration generate liposomes.

Rojanarat et al. (2011) developed proliposome powders of the anti-tubercular drug, isoniazid, as dry powders for inhalation [84]. The proliposomes were prepared by preparing a lipid solution of L- $\alpha$ soybean phosphatidylcholine and cholesterol in ethanol. After dissolution of isoniazid in this solution and dispersion of microparticulate mannitol, the formed suspension was sonicated and then spray dried. The encapsulated efficiency of isoniazid in the proliposomes ranged between $18-30 \%$ while upon reconstitution with distilled water, liposome vesicles with sizes in the nano range were formed. The in vitro aerosolisation performance of the proliposomes was evaluated using the ACI and FPFs of $15-35 \%$ were observed. The isoniazid proliposomes were shown to be non-toxic to respiratory-associated cells and were also found to exhibit enhanced anti-mycobacterial activity against Mycobacterium bovis-infected alveolar macrophages compared to free isoniazid.

Patil-Gadhe et al. (2014) applied Quality by Design (QbD) to study the in vitro and in vivo performance of rifapentine proliposomes for pulmonary inhalation for the treatment of tuberculosis [85]. The rifapentine proliposomes were prepared in a single step by applying spray drying and the independent variables (i.e., drug to hydrogenated soya phosphatidylcholine ratio and type of charged lipid) were optimised using experimental design. The optimised formulation contained drug: hydrogenated soya phosphatidylcholine ratio of 1:2 and stearyl amine as the charged lipid. In vitro aerosolisation using the Westech 8 stage cascade impactor showed that the optimised formulation 
exhibited a MMAD of $1.56 \pm 0.16 \mu \mathrm{m}$ and FPF of $92.5 \pm 1.5 \%$. Drug release was sustained and followed Higuchi diffusion kinetics.

Ye et al. (2018) developed a combination proliposome formulation containing both hydrophilic tobramycin and hydrophobic clarithromycin via a core-carrier approach, for the treatment of respiratory infections caused by Pseudomonas aeruginosa [86]. The combinatory proliposomes were produced by spray drying a suspension comprising spray-dried mannitol $(0.45 \% w / v)$ and spray-dried tobramycin $(0.05 \% w / v)$ particles suspended in an ethanolic lipid solution of clarithromycin $(0.05 \% w / v)$, soybean phosphatidylcholine and cholesterol (Figure 10). The lipid layer coated on the surface of the dry proliposome particles provided moisture protection and sustained drug release properties when compared to the pure drugs. The optimized proliposome formulation was stable after three months at $25{ }^{\circ} \mathrm{C} / 60 \% \mathrm{RH}$ and showed a synergistic antimicrobial activity against planktonic Pseudomonas aeruginosa cultures and biofilms. It was concluded that the core-carrier method coupled with spray drying provided a novel strategy for the preparation of combinatory antibiotic proliposomes.

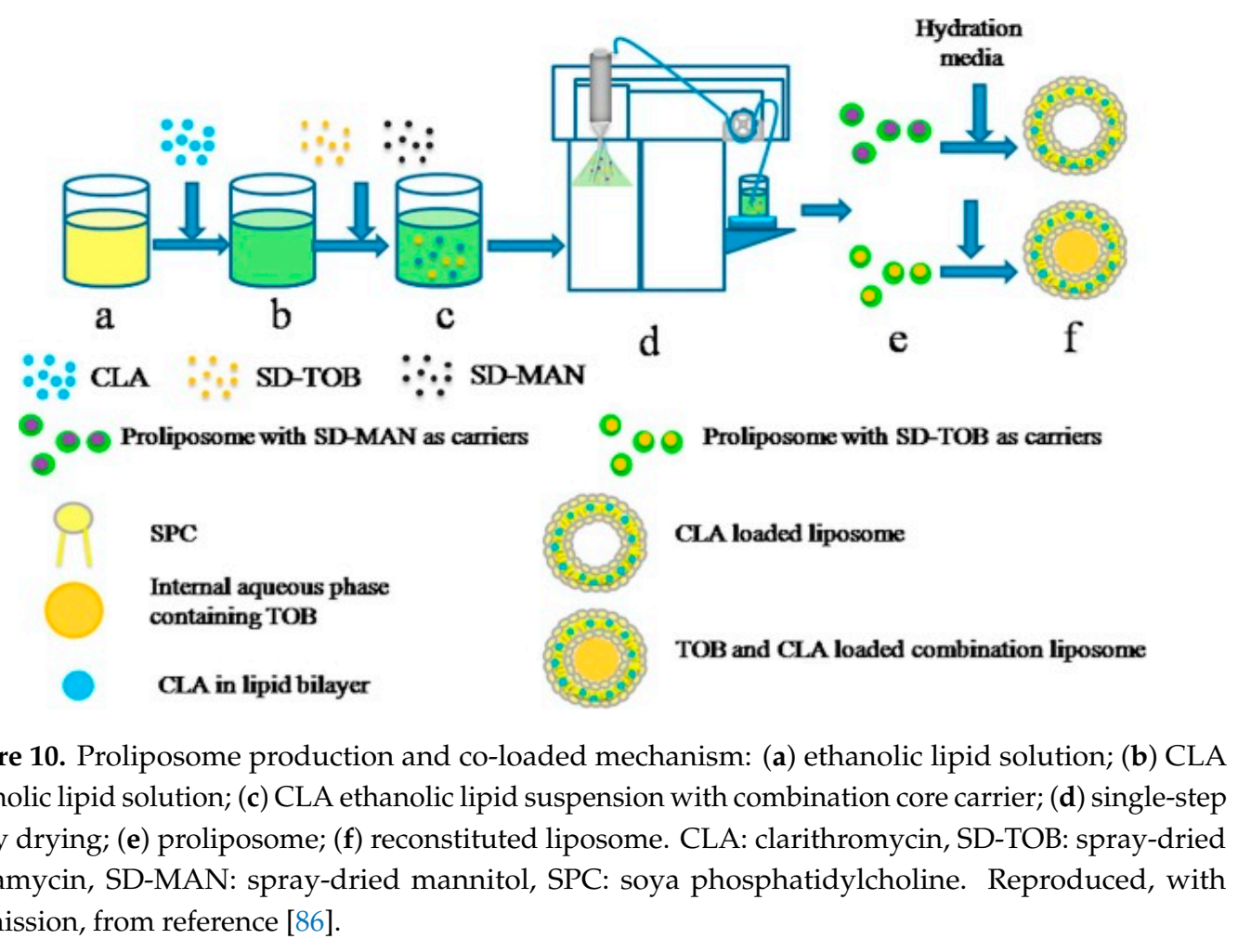

Solid lipid nanoparticles (SLNs) consist of a monolayer phospholipid shell and a solid hydrophobic core. Lipophilic drugs can be entrapped within the lipid matrix either by dispersing or dissolving the materials in the molten lipid. A review on SLNs for pulmonary drug delivery has been provided by Weber et al. (2014) [87]. Gaspar et al. (2016) prepared inhalable SLNs containing the anti-tubercular drug, rifabutin [88]. Rifabutin-loaded glyceryl dibehenate and glyceryl tristearate SLNs were loaded on microspheres of appropriate size through spray drying, using suitable excipients (i.e., mannitol and trehalose). In vitro deposition using the TSI confirmed that the microspheres can reach the deep lung. Upon microsphere dissolution in aqueous media, SLNs were readily reformed, retaining their physicochemical characteristics. The anti-mycobacterial activity of the SLNs was evaluated in a murine model of infection with a Mycobacterium tuberculosis strain H37Rv and was found to be enhanced compared to non-treated animals. Cell viability studies using Calu-3 and A549 cell lines showed low cytotoxicity for the SLNs indicating their potential for the pulmonary delivery of anti-tubercular agents. The anti-asthmatic salbutamol sulfate presents oral bioavailability problems due to its first pass hepatic metabolism, shorter half-life, and systemic toxicity at high doses. Honmane et al. (2019) developed nanoliposomal salbutamol sulfate dry powder for inhalation [89]. Liposomes were prepared 
using the thin-film hydration method and experimental design was applied to optimise formulation parameters, namely the vesicle size and the drug entrapment. The optimised liposomal dispersion had a size of $167.2 \mathrm{~nm}$ and was spray dried to produce inhalable dry powders. The optimised liposomal formulation achieved prolonged in vitro drug release ( $>90 \%$ up to $14 \mathrm{~h}$ ) following Higuchi's controlled release model.

Liposomal encapsulated drug nanocrystals have been proposed as a formulation approach to overcome some of the challenges in the production of nanocrystals (e.g., size control in bottom-up processing and surface amorphisation in top-down processing) and also modulate the release rate of active ingredient [90]. Liposomal encapsulated drug nanocrystals are a complex formulation produced by a simple freeze-thaw step resulting in the formation of a single drug nanocrystal residing within the interior of a liposome. Khatib et al. (2019) evaluated the feasibility of developing inhalable dry powders of liposomal encapsulated ciprofloxacin nanocrystals for controlled drug release of the antibiotic (Figure 11) [91]. Dry powders of the liposomal encapsulated nanocrystals were produced by loading the drug in unilamellar liposomes which were then processed by a freeze-thaw step and solidified by spray drying. In vitro aerosolisation of the spray-dried powders carried out using the NGI demonstrated high FPFs around $70 \%$. After reconstitution of the powders in saline buffer, the presence of ciprofloxacin nanocrystals was confirmed by cryogenic transmission electron microscopy. From the examined formulations with varying sucrose to lipid ratios, the 2:1 weight ratio demonstrated prolonged release of ciprofloxacin. It was concluded that liposomal encapsulated ciprofloxacin nanocrystals are suitable for inhalation aerosol delivery and controlled drug release that can be administered as a once-daily formulation.

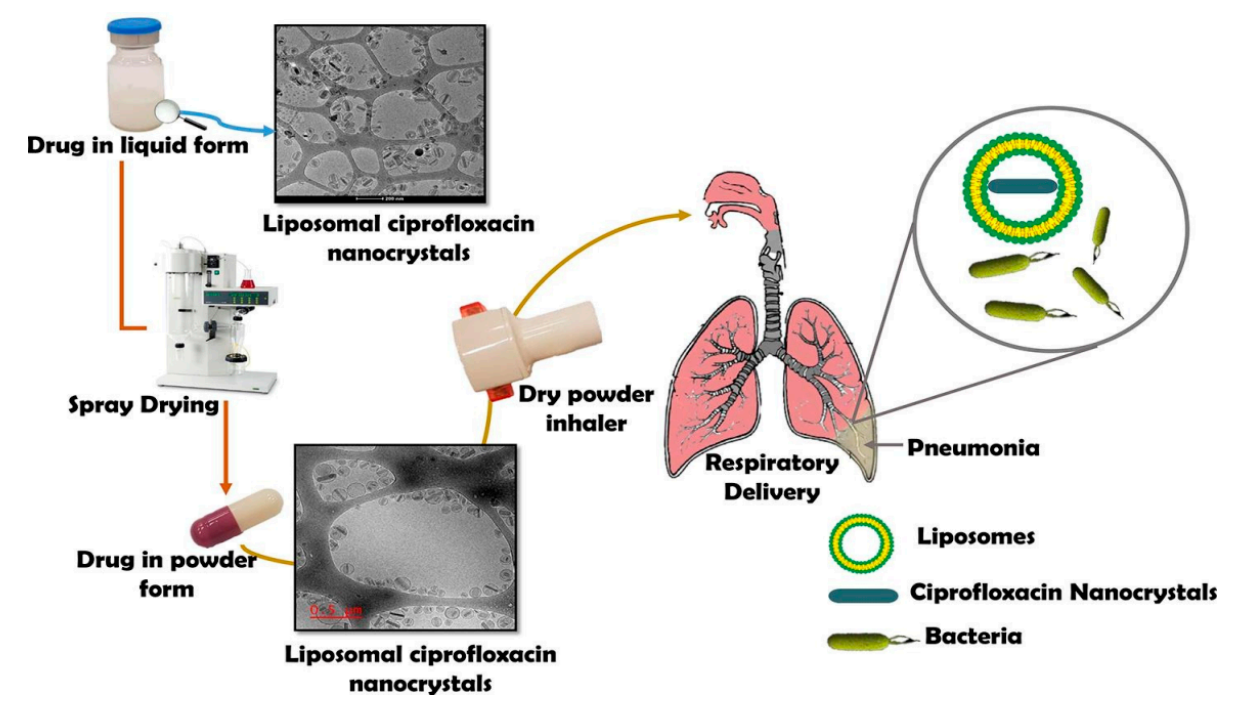

Figure 11. Ciprofloxacin nanocrystal liposomal powders produced by spray drying liposomal drug nanocrystals containing sucrose as cryoprotectant. Taken from Khatib et al. (2019) [91].

Based on the results of the aforementioned studies, proliposomes, SLNs and nanocrystal liposomal systems have shown that lipidic spray-dried powder formulations can be developed for the pulmonary delivery of drugs with various physicochemical characteristics and pharmacological action including anti-tubercular agents and antibiotics. The main advantage of these formulations is their ability to combine the stability of the solid formulations with the potential of controlled release associated with lipid-based delivery.

\subsection{Polymeric Nanoparticles}

Polymeric NPs are defined as solid colloidal submicron particles which are made up of polymers of natural, synthetic or semi-synthetic origin. They can act as vehicles for small molecular weight drugs 
and biomolecules. Depending on the method of preparation, NPs can be encapsulated in polymer-based carriers, loaded on the surface of the polymer or can be dispersed in the polymeric matrix. The most commonly used polymers for the formation of polymeric NPs are: poly(lactic-co-glycolic acid) (PLGA), polyethylene glycol (PEG), alginate, gelatin and chitosan. A review on the recent developments of polymeric NPs as drug delivery system is provided by Sur et al. (2018) while Lebhardt et al. (2010) discuss the polymers with reduced toxic potential and biodegradable nature that have been used for drug delivery to the lungs [92,93].

Ohashi et al. (2009) prepared dry powders consisting of polymeric NPs of the anti-tubercular drug, rifampicin [94]. Rifampicin and PLGA were dissolved in acetone/methanol while an aqueous solution of mannitol was also formed. The two solutions were spray dried through different liquid passages of the four-fluid nozzle and rifampicin/PLGA NP-containing mannitol microspheres were formed (Figure 12). Using the ACI, the microspheres showed a good in vitro aerosol performance, achieving FPF around 30\%. The in vivo uptake by the alveolar macrophages in the lung of rats was found to be higher for the rifampicin/PLGA mannitol microspheres compared to the microspheres without mannitol.

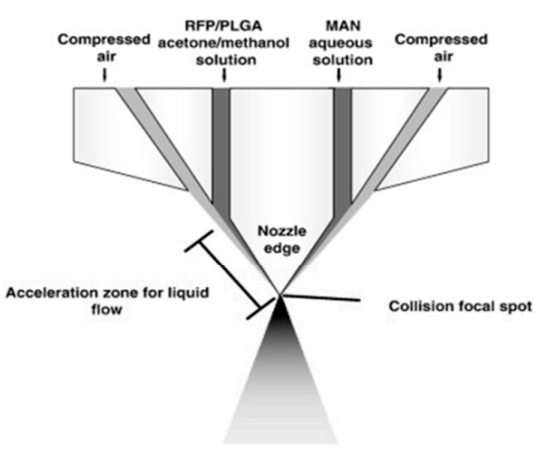

(a)

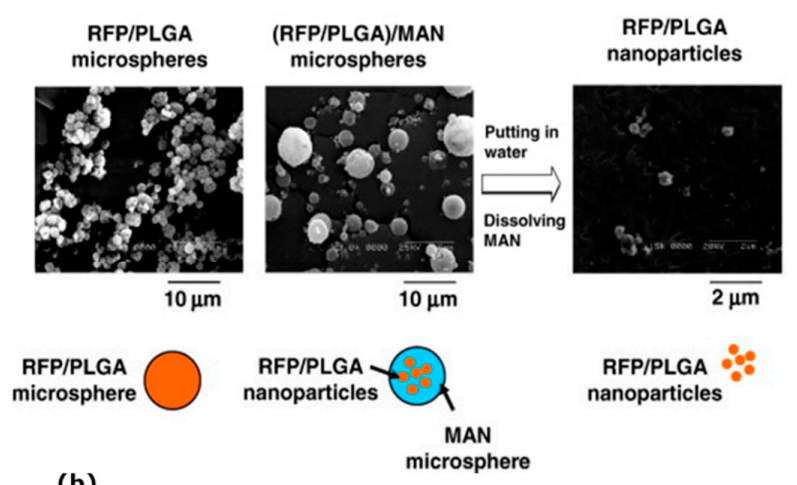

Figure 12. (a) Schematic of a four-fluid nozzle and (b) scanning electron microscopy images of RFP/PLGA microspheres, (RFP/PLGA) NPs embedded in mannitol and RFP/PLGA NPs upon redispersion of the NP agglomerates in water. RFP: rifampicin, PLGA: poly(lactic-co-glycolic acid) and MAN: mannitol. Reproduced, with permission, from reference [94].

To overcome obstacles such as the poor solubility, instability, erratic bioavailability and side effects of the immunosuppressant, tacrolimus, for the treatment of pulmonary arterial hypertension, Wang et al. (2016) developed nanocomposite microparticles as dry powders for inhalation [95]. Tacrolimus was encapsulated in acetalated dextran via emulsion solvent evaporation and tacrolimus-loaded polymeric NPs of approximately $200 \mathrm{~nm}$ were formed. Using spray drying of the NPs in the presence of mannitol, NP agglomerates with an average geometric diameter of around $2 \mu \mathrm{m}$ and raisin-like shape were formed. In vitro aerosolisation testing demonstrated a FPF of $81.0 \%$ and a MMAD of $3.57 \pm 0.57 \mu \mathrm{m}$, allowing them to deposit in the deep regions of the respiratory tract. A549 human adenocarcinoma alveolar epithelial cells were used as an in vitro model for the evaluating the effect of the NP agglomerates on their viability. No significant effect on the viability of the A549 cells was observed, indicating the non-cytotoxic effect of the NP agglomerates. Based on the results of this study as well as follow-up studies from the same research group, it was concluded that acetalated dextran-based NP agglomerates exhibit promising potential in application of therapeutics for pulmonary drug delivery $[96,97]$.

Rezazadeh et al. (2018) synthesised mixed polymeric micelles based on tocopherol succinatepolyethylene glycol 1000 and $5000 \mathrm{Da}$ and loaded them with the chemotherapeutic agent, paclitaxel [98]. The optimised micelles were spray dried with lactose to produce dry powders for inhalation. The drug release rate from different formulations was slow as only $30 \%$ was released within the first $72 \mathrm{~h}$. The cytotoxic activity of the drug nanomicelles was found to be higher compared to the free drug when tested against the A549 cell line. 
In-vitro deposition testing using the ACI indicated that spray drying of the drug nanomicelles with lactose resulted in 60\% FPF. The developed microparticles containing paclitaxel nanomicelles were considered as a potential formulation for the treatment of lung cancer.

NP agglomerates composed of nanomicelles produced by spray drying were developed by Farhangi et al. (2019) aiming to increase the residence time in the lungs and enhance the antimicrobial effects of ciprofloxacin [99]. Upon optimisation using desing of experiments, NP agglomerates with median diameter of $1.7 \mu \mathrm{m}$ and FPF of $60 \%$ where produced when mannitol was used as the matrix former and L-phenylalanine as anti-adhesion agent. The antimicrobial effects of ciprofloxacin against microorganisms, namely Pseudomonas aeruginosa, Klebsiella pneumoniae and Streptococcus pneumoniae were increased significantly. Therefore, the method could be used to prepare an optimum dry powder for inhalation consisting of polymeric nanomicelles for treatment of pulmonary infections.

The results of the aforementioned studies show that the great variety of available polymers together with different methods of preparation when combined with spray drying as a solidification step can lead to respirable NP agglomerates with improved efficacy and controlled drug release.

\section{Application of Alternative Spray-Drying Techniques}

\subsection{Nano Spray Drying}

As stated previously (refer to Section 3.4), due to their limited collection efficiency for particles below $2 \mu \mathrm{m}$, conventional spray dryers are not suited to produce NPs. An alternative spray dryer model, the Nano Spray Dryer B-90 was introduced in 2009 by Buchi (Buchi Labortechnik AG) to facilitate the production of NPs (Figure 13). The technological novelty of this dryer lies on three key features: (i) the vibrating mesh spray technology, (ii) the gentle laminar drying flow, and (iii) the electrostatic particle collector. These improvements result in enhanced sample recovery (up to 90\%) compared to conventional spray driers [100]. A detailed review on the principles of operation of the Nano Spray Dryer and its application for the encapsulation of pharmaceuticals has been provided by Arpagaus et al. (2018) [101].
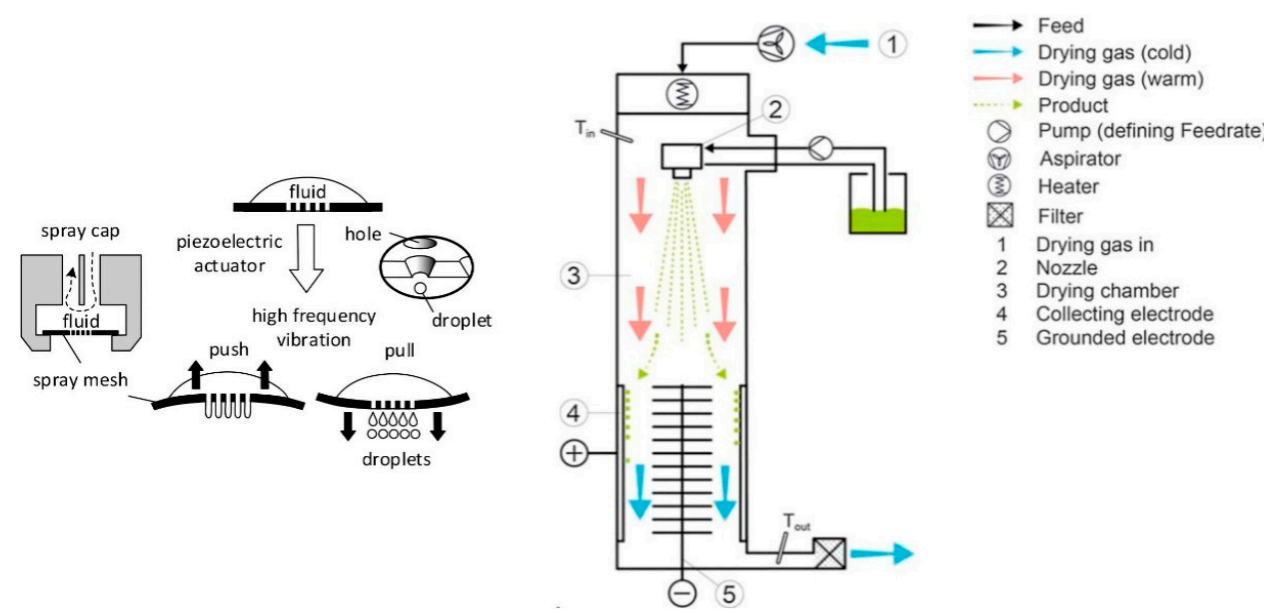

Figure 13. Schematic of a nano spray dryer and its functional principles. Taken from Arpagaus et al. (2018) [101].

Nano spray drying is an efficient method for the formation of NPs, especially when the smaller mesh aperture size $(4.0 \mu \mathrm{m})$ is used and the feed solution is highly diluted $(\sim 0.1 \% w / w)$ [102]. The use of nano spray drying has been reported for the production of NP-based dry powders for inhalation. Bürki et al. (2011) used $\beta$-galactosidase as a model protein and studied the preparation of respirable protein powders containing trehalose (stabiliser) using the Nano Spray Dryer B-90 [103]. The effects of inlet temperature, spray cap size and ethanol concentration in the spray solution on the performance of the process and the quality attributes of the particles were evaluated. Inlet temperature influenced 
the enzyme activity, but the effect was dependent on the spray cap size. Higher product recovery was achieved with lower inlet temperatures, higher ethanol content and smaller cap sizes. The protein exhibited higher storage stability when spray dried without ethanol and when a larger spray cap size was used.

Schoubben et al. (2014) produced inhalable powders of the anti-tubercular agent, capreomycin sulphate using the Nano Spray Dryer B-90 [104]. Experimental design was used to optimise the process, namely the membrane pore size, the inlet temperature and the solution concentration. Optimised capreomycin particles formulated with lactose exhibited $\sim 27 \%$ respirable fraction when tested using the TSI. These results were found to be promising and spray-dried formulations of capreomycin sulphate have been enrolled in clinical trials for the treatment of multi-drug resistant tuberculosis. Regarding particle engineering for pulmonary drug delivery, the positive effect of L-leucine on the aerosolisation performance of dry powders has also been demonstrated by various studies using nano spray drying for their production $[105,106]$.

\subsection{Supercritical $\mathrm{CO}_{2}$-Assisted Spray Drying}

Supercritical fluids (SCFs) are fluids which exist at temperature and pressure conditions above their critical point. SCFs present gas-liquid transport properties. Supercritical carbon dioxide $\left(\mathrm{sc}^{-} \mathrm{CO}_{2}\right)$ is the most widely used SCF in pharmaceutical engineering as with a critical temperature $31.15^{\circ} \mathrm{C}$ and pressure of 7.4 MPa, it is the only compound that can be used as a "green solvent" [107]. Other advantages include its non-toxic nature, low cost and recyclability.

Supercritical-assisted atomization, also referred to as supercritical $\mathrm{CO}_{2}$-assisted spray drying (SASD) has been used for the production of dry powder formulation with pharmaceutical applications. SASD is a single-step spray-based process, where sc- $\mathrm{CO}_{2}$ and the solution containing the active ingredients are pumped simultaneously into a static mixture that promotes a near-equilibrium mixing. The mixture is sprayed through the nozzle into the precipitator at atmospheric pressure, where the flow of heated compressed air assists rapid liquid solvent evaporation from the particles which are finally separated and collected in the cyclone (Figure 14). A review on engineering of dry powder formulations using SASD is provided by Aguiar-Ricardo (2017) [108].

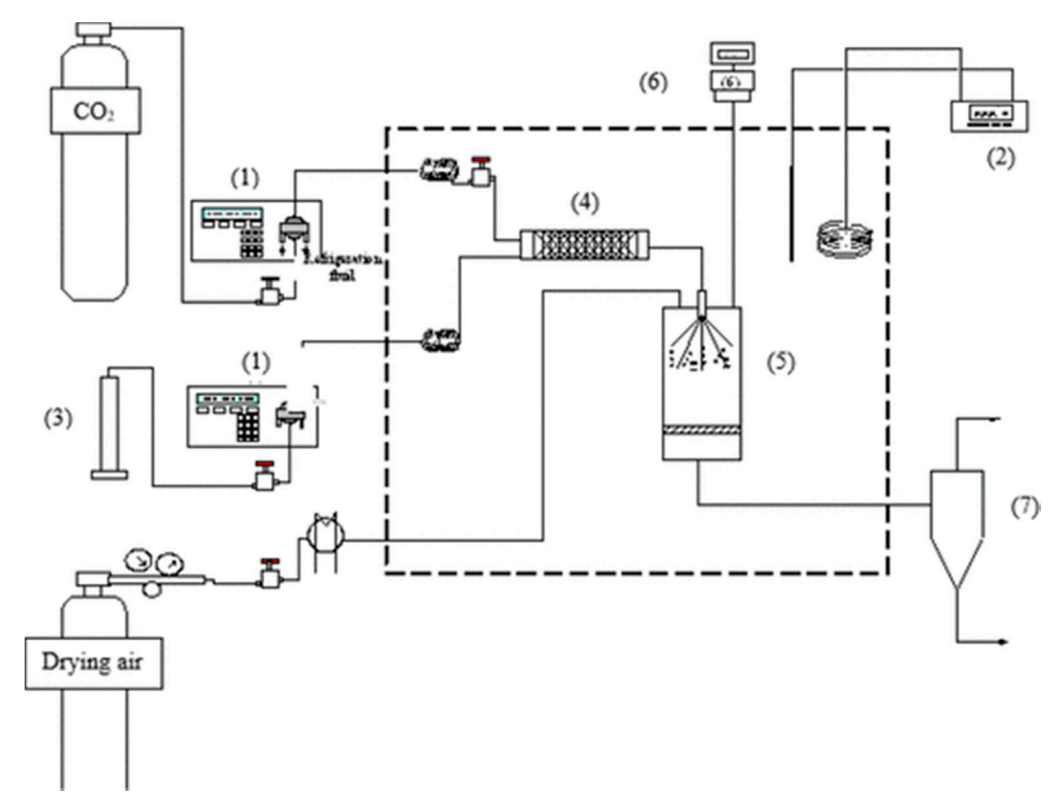

Figure 14. Schematic of the supercritical $\mathrm{CO}_{2}$-assisted spray drying (SASD) apparatus: (1) high-pressure liquid chromatography pump, (2) temperature controller, (3) container with liquid solution, (4) saturator, (5) precipitator, (6) manometer and (7) high efficiency cyclone. Reproduced, with permission, from reference [109]. 
For a targeted and effective delivery of therapeutic biomolecules to the deep lungs, Silva et al. (2017) incorporated functionalized gold NPs into respirable microparticles [110]. The gold NPs were functionalized with biocompatible fluorescent coatings and conjugated with a peptide for targeted lung cancer delivery. The functionalized gold NPs were then embedded into a chitosan matrix by SASD, resulting in nanos-in-micros dry powder formulations. The rapid process of SASD was found to eliminate the possibility of thermal degradation making this technology suitable for conjugation of therapeutic molecules. The engineered formulations exhibited FPFs ranging from 30 to $40 \%$ when tested using the ACI. They also exhibited optimal biodegradation and release profiles, which enabled a sustained and controlled release of the embedded NPs with enhanced cellular uptake. The approach of nanos-in-micros using SASD was also applied for encapsulation of strawberry-like gold-coated magnetite nanocomposites and ibuprofen in chitosan matrix [111]. The dry powders exhibited satisfactory morphology and aerodynamic performance with FPF $48-55 \%$ when tested using the ACI. Ibuprofen showed a rapid release at $\mathrm{pH} 6.8$, the $\mathrm{pH}$ of lung cancer. It was concluded that these proof-of-concept studies support the development of dry powders of gold nanocomposites by SASD as potential theragnostic agents to be administered to the lungs.

Restani et al. (2015) formulated POxylated polyurea dendrimer-based NPs as dry powders for inhalation [112]. The nanoparticles were loaded with the anticancer drugs paclitaxel and doxorubicin and micronised with chitosan by using SASD. The produced dry powder formulations exhibited FPF around $30 \%$ when tested using the ACI. In vitro studies showed that engineered formulations exhibited a higher chemotherapeutic effect than the free paclitaxel formulations in adenocarcinoma cell, suggesting their potential for inhalation chemotherapy.

\section{Conclusions}

Controlled agglomeration of NPs to micron-sized clusters is a formulation strategy which combines the advantages of nanotherapeutics with the aerodynamics of microparticles which are required for efficient pulmonary drug delivery. Spray drying is a universal technique for the conversion of colloidal suspensions containing NPs to microparticles. The great variety of NP-based drug delivery systems (e.g., nanocrystals, lipid-based NPs, polymeric NPs, inorganic NPs), formulation and process parameters (e.g., excipients and inlet temperature) along with the advances in the technology of the spray-drying equipment (e.g., multiple-fluid nozzles, nano spray drying, supercritical $\mathrm{CO}_{2}$-assisted spray drying) allow the formation of inhalable NP agglomerates of drugs and biomolecules. Based on the results of the studies reported in this review, NP agglomerates as dry powder for inhalation hold the potential for enhanced dissolution of poorly water-soluble drugs, targeted delivery to the respiratory tract, modified release as well as improved efficacy and safety.

Even though each type of NP agglomerates has each own unique strengths and areas of application, it is of the opinion of the authors that the nanocrystalline agglomerates are the formulation platform with the highest probability to be translated to a marketed medicinal product. This is because the particles produced are crystalline and the excipients used as matrix formers (i.e., mannitol and L-leucine) have already been authorised for this route of administration. Future studies should focus on scaling-up the production of NP agglomerates and their downstream processing (i.e., filling capsules or blisters).

Author Contributions: Conceptualization, M.M. and I.N.; writing—original draft preparation, M.M., A.C. and I.N.; writing-review and editing, M.M., I.N., S.M. and K.K.; visualization, M.M., S.M.; supervision, M.M. and I.N. All authors have read and agreed to the published version of the manuscript.

Funding: This research received no external funding.

Conflicts of Interest: The authors declare no conflict of interest. 


\section{References}

1. Anselmo, A.C.; Gokarn, Y.; Mitragotri, S. Non-invasive delivery strategies for biologics. Nat. Rev. Drug Discov. 2019, 18, 19-40. [CrossRef]

2. Murnane, D.; Hutter, V.; Harang, M. Pharmaceutical aerosols and pulmonary drug delivery. In Aerosol Science: Technology and Applications, 1st ed.; Coldbeck, I., Lazaridis, M., Eds.; John Wiley and Sons: Hoboken, NJ, USA, 2014; pp. 221-269.

3. Jabbal, S.; Poli, G.; Lipworth, B. Does size really matter? Relationship of particle size to lung deposition and exhaled fraction. J. Allergy Clin. Immunol. 2017, 139, 2013-2014.e2011. [CrossRef] [PubMed]

4. Heyder, J. Deposition of inhaled particles in the human respiratory tract and consequences for regional targeting in respiratory drug delivery. Proc. Am. Thorac. Soc. 2004, 1, 315-320. [CrossRef] [PubMed]

5. Tatkare, D. Copd and Asthma Devices Market by Inhalers Type (Drug Powder, Metered Dose, Soft Mist), Nebulizers (Compressor, Ultrasonic, Mesh). Available online: https://www.alliedmarketresearch.com/COPDasthma-devices-market (accessed on 21 May 2020).

6. Malamatari, M. Engineering Nanoparticle Agglomerates as Dry Powders for Pulmonary Drug Delivery; UCL (University College London): London, UK, 2016.

7. Darquenne, C. Aerosol Deposition in health and disease. J. Aerosol Med. Pulm. Drug Deliv. 2012, $25,140-147$. [CrossRef] [PubMed]

8. Kourmatzis, A.; Cheng, S.; Chan, H.K. Airway geometry, airway flow, and particle measurement methods: Implications on pulmonary drug delivery. Expert Opin. Drug Deliv. 2018, 15, 271-282. [CrossRef]

9. Martin, R.A.; Moore, C.P.; Finlay, W.H. Models of deposition, pharmacokinetics, and intersubject variability in respiratory drug delivery. Expert Opin. Drug Deliv. 2018, 15, 1175-1188. [CrossRef]

10. He, Y.; Liang, Y.; Han, R.; Lu, W.L.; Wo Mak, J.C.; Zheng, Y. Rational particle design to overcome pulmonary barriers for obstructive lung diseases therapy. J. Control. Release 2019, 314, 48-61. [CrossRef]

11. Islam, N.; Gladki, E. Dry powder inhalers (DPIs) - A review of device reliability and innovation. Int. J. Pharm. 2018, 360, 1-11. [CrossRef]

12. Islam, N.; Cleary, M.J. Developing an efficient and reliable dry powder inhaler for pulmonary drug delivery-A review for multidisciplinary researchers. Med. Eng. Phys. 2012, 34, 409-427. [CrossRef]

13. Hoppentocht, M.; Hagedoorn, P.; Frijlink, H.W.; de Boer, A.H. Technological and practical challenges of dry powder inhalers and formulations. Adv. Drug Deliv. Rev. 2014, 75, 18-31. [CrossRef]

14. De Boer, A.H.; Hagedoorn, P.; Hoppentocht, M.; Buttini, F.; Grasmeijer, F.; Frinjlink, H.W. Dry Powder Inhalation: Past, Present and Future. Expert Opin. Drug Deliv. 2017, 14, 499-512. [CrossRef] [PubMed]

15. Buttini, F.; Rozou, S.; Rossi, A.; Zoumpliou, V.; Rekkas, D.M. The application of Quality by Design framework in the pharmaceutical development of dry powder inhalers. Eur. J. Pharm. Sci. 2018, 13, 64-76. [CrossRef] [PubMed]

16. Levy, M.L.; Carroll, W.; Izquierdo Alonso, J.L.; Keller, C.; Lavorini, F.; Lehtimaki, L. Understanding Dry Powder Inhalers: Key Technical and Patient Preference Attributes. Adv. Ther. 2019, 36, 2547-2557. [CrossRef] [PubMed]

17. Pilcer, G.; Amighi, K. Formulation strategy and use of excipients in pulmonary drug delivery. Int. J. Pharm. 2010, 392, 1-19. [CrossRef] [PubMed]

18. Al-Hallak, M.H.D.K.; Sarfaz, M.K.; Azarmi, S.; Roa, W.H.; Finlay, W.H.; Lobenberg, R. Pulmonary delivery of inhalable nanoparticles: Dry powder inhalers. Ther. Deliv. 2011, 2, 1313-1324. [CrossRef] [PubMed]

19. Healy, A.M.; Amaro, M.I.; Paluch, K.J.; Tajber, L. Dry powders for oral inhalation free of lactose carrier particles. Adv. Drug Deliv. Rev. 2014, 75, 32-52. [CrossRef] [PubMed]

20. Gradon, L.; Sosnowski, T.R. Formation of particles for dry powder inhalers. Adv. Powder Technol. 2014, 25, 43-55. [CrossRef]

21. Brunaugh, A.D.; Smyth, H.D.C. Formulation Techniques for High Dose Dry Powders. Int. J. Pharm. 2018, 25, 489-498. [CrossRef]

22. Hadiwinoto, G.D.; Kwok, P.C.L.; Lakerveld, R. A Review on Recent Technologies for the Manufacture of Pulmonary Drugs. Ther. Deliv. 2018, 9, 47-70. [CrossRef]

23. Nikolakakis, I.; Newton, J.M. Solid state adsorption of antibiotics onto sorbitol. J. Pharm. Pharmacol. 1989, 41, 145-148. [CrossRef] 
24. Nikolakakis, I.; Newton, J.M.; Malamataris, S. Solid state 'adsorption' of fine antibiotic powders onto sorbitol: Effects of particle size, state of sorbed water and surface free energy characteristics. Eur. J. Pharm. Sci. Offic. J. Eur. Fed. Pharm. Sci. 2002, 17, 229-238. [CrossRef]

25. Grasmeijer, F.; Grasmeijer, N.; Hagedoorn, P.; Frijlink, H.W.; Haaije de Boer, A. Recent advances in the fundamental understanding of adhesive mixtures for inhalation. Curr. Pharm. Des. 2015, 21, 5900-5914. [CrossRef] [PubMed]

26. Keck, C.M.; Müller, R.H. Drug nanocrystals of poorly soluble drugs produced by high pressure homogenisation. Eur. J. Pharm. Biopharm. Offic. J. Arb. Fur Pharm. Verfahr. E.V 2006, 62, 3-16. [CrossRef] [PubMed]

27. Nikolakakis, I.; Pilpel, N. Effect of particle shape on the tensile strengths of powders. Powder Technol. 1985, 42, 279-283. [CrossRef]

28. Florence, A.T.; Attwood, D. Physicochemical principles of pharmacy. In Manufacture, Formulation and Clinical Use; Pharmaceutical Press: London, UK, 2015.

29. Buckton, G.; Beezer, A.E. The relationship between particle size and solubility. Int. J. Pharm. 1992, 82, R7-R10. [CrossRef]

30. Williams, H.D.; Trevaskis, N.L.; Charman, S.A.; Shanker, R.M.; Charman, W.N.; Pouton, C.W.; Porter, C.J.H. Strategies to address low drug solubility in discovery and development. Pharmacol. Rev. 2013, 65, 315-499. [CrossRef]

31. Malamatari, M.; Taylor, K.M.G.; Malamataris, S.; Douroumis, D.; Kachrimanis, K. Pharmaceutical nanocrystals: Production by wet milling and applications. Drug Discov. Today 2018, 23, 534-547. [CrossRef]

32. Iyer, R.; Hsia, C.C.; Nguyen, K.T. Nano-therapeutics for the lung: State-of-the-art and future perspectives. Curr. Pharm. Des. 2015, 21, 5233-5244. [CrossRef]

33. Tolman, J.A.; Williams, R.O. Advances in the pulmonary delivery of poorly water-soluble drugs: Influence of solubilization on pharmacokinetic properties. Drug Dev. Ind. Pharm. 2010, 36, 1-30. [CrossRef]

34. Wu, L.; Zhang, J.; Watanabe, W. Physical and chemical stability of drug nanoparticles. Adv. Drug Deliv. Rev. 2011, 63, 456-469. [CrossRef]

35. Rogueda, P.G.A.; Traini, D. The nanoscale in pulmonary delivery. Part 1: Deposition, fate, toxicology and effects. Expert Opin. Drug Deliv. 2007, 4, 595-606. [CrossRef] [PubMed]

36. Watts, A.; Williams, R. Nanoparticles for pulmonary delivery. In Controlled Pulmonary Drug Delivery; Springer: Berlin/Heidelberg, Germany, 2011; pp. 335-366.

37. El-Gendy, N.; Gorman, E.M.; Munson, E.J.; Berkland, C. Budesonide nanoparticle agglomerates as dry powder aerosols with rapid dissolution. J. Pharm. Sci. 2009, 98, 2731-2746. [CrossRef]

38. Muralidharan, P.; Malapit, M.; Mallory, E.; Hayes, D., Jr.; Mansour, H.M. Inhalable nanoparticulate powders for respiratory delivery. Nanomed. Nanotechnol. Biol. Med. 2015, 11, 1189-1199. [CrossRef]

39. Malamatari, M.; Somavarapu, S.; Taylor, K.M.G.; Buckton, G. Solidification of nanosuspensions for the production of solid oral dosage forms and inhalable dry powders. Expert Opin. Dry Deliv. 2016, 13, 435-450. [CrossRef] [PubMed]

40. Silva, A.S.; Tavares, M.T.; Aguiar-Ricardo, A. Sustainable strategies for nano-in-micro particle engineering for pulmonary delivery. J. Nanoparticle Res. 2014, 16, 2602. [CrossRef]

41. Vehring, R.; Snyder, H.; Lechuga-Ballesteros, D. Spray drying. In Drying Technologies for Biotechnology and Pharmaceutical Applications, 1st ed.; Ohtake, S., Izutsu, K., Lechuga-Ballesteros, D., Eds.; Wiley-VCH Verlag GmbH: Weinheim, Germany, 2020; pp. 179-216.

42. Partheniadis, I.; Karakasidou, P.; Vergkizi, S.; Nikolakakis, I. Spectroscopic examination and release of microencapsulated oregano essential oil. Admet Dmpk 2017, 5, 224-233. [CrossRef]

43. Vehring, R. Pharmaceutical particle engineering via spray drying. Pharm. Res. 2008, 25, 999-1022. [CrossRef]

44. Masters, K. The Spray Drying Handbook; Longman Scientific Publication: New York, NY, USA, 1991; pp. 329-556.

45. Dobry, D.E.; Settell, D.M.; Baumann, J.M.; Ray, R.J.; Graham, L.J.; Beyerinck, R.A. A model-based methodology for spray-drying process development. J. Pharm. Innov. 2009, 4, 133-142. [CrossRef] [PubMed]

46. Elversson, J.; Millqvist-Fureby, A. Particle size and density in spray drying-Effects of carbohydrate properties. J. Pharm. Sci. 2015, 94, 2049-2060. [CrossRef] [PubMed]

47. Cheow, W.S.; Li, S.; Hadinoto, K. Spray drying formulation of hollow spherical aggregates of silica nanoparticles by experimental design. Chem. Eng. Res. Des. 2010, 88, 673-685. [CrossRef] 
48. Kemp, I.C.; Wadley, R.; Hartwig, T.; Cocchini, U.; See-Toh, Y.; Gorringe, L.; Fordham, K.; Ricard, F. Experimental study of spray drying and atomization with a two-fluid nozzle to produce inhalable particles. Dry. Technol. 2013, 31, 930-941. [CrossRef]

49. Mezhericher, M.; Levy, A.; Borde, I. Spray drying modelling based on advanced droplet drying kinetics. Chem. Eng. Process. Process Intensif. 2010, 49, 1205-1213. [CrossRef]

50. Osman, A.; Goehring, L.; Patti, A.; Stitt, H.; Shokri, N. Fundamental investigation of the drying of solid suspensions. Ind. Eng. Chem. Res. 2017, 56, 10506-10513. [CrossRef]

51. Tsapis, N.; Bennett, D.; Jackson, B.; Weitz, D.A.; Edwards, D.A. Trojan particles: Large porous carriers of nanoparticles for drug delivery. Proc. Natl. Acad. Sci. USA 2002, 99, 12001-12005. [CrossRef] [PubMed]

52. Wei, Y.; Deng, W.; Chen, R.-H. Effects of insoluble nano-particles on nanofluid droplet evaporation. Int. J. Heat Mass Transf. 2016, 97, 725-734. [CrossRef]

53. Torge, A.; Grützmacher, P.; Mücklich, F.; Schneider, M. The influence of mannitol on morphology and disintegration of spray-dried nano-embedded microparticles. Eur. J. Pharm. Sci. 2017, 104, 171-179. [CrossRef] [PubMed]

54. Maa, Y.F.; Nguyen, P.A.; Sit, K.; Hsu, C.C. Spray-drying performance of a bench-top spray dryer for protein aerosol powder preparation. Biotechnol. Bioeng. 1998, 60, 301-309. [CrossRef]

55. Maury, M.; Murphy, K.; Kumar, S.; Shi, L.; Lee, G. Effects of process variables on the powder yield of spray-dried trehalose on a laboratory spray-dryer. Eur. J. Pharm. Biopharm. 2005, 59, 565-573. [CrossRef] [PubMed]

56. Kemp, I.C.; Hartwig, T.; Herdman, R.; Hamilton, P.; Bisten, A.; Bermingham, S. Spray drying with a two-fluid nozzle to produce fine particles: Atomization, scale-up, and modeling. Dry. Technol. 2016, 34, 1243-1252. [CrossRef]

57. Edwards, D.A.; Hanes, J.; Caponetti, G.; Hrkach, J.; Ben-Jebria, A.; Eskew, M.L.; Mintzes, J.; Deaver, D.; Lotan, N.; Langer, R. Large porous particles for pulmonary drug delivery. Science 1997, 276, 1868-1871. [CrossRef]

58. Healy, A.M.; McDonald, B.F.; Tajber, L.; Corrigan, O.I. Characterisation of excipient-free nanoporous microparticles (npmps) of bendroflumethiazide. Eur. J. Pharm. Biopharm. 2008, 69, 1182-1186. [CrossRef] [PubMed]

59. Nolan, L.M.; Tajber, L.; McDonald, B.F.; Barham, A.S.; Corrigan, O.I.; Healy, A.M. Excipient-free nanoporous microparticles of budesonide for pulmonary delivery. Eur. J. Pharm. Sci. 2009, 37, 593-602. [CrossRef]

60. Paluch, K.J.; Tajber, L.; Corrigan, O.I.; Healy, A.M. Impact of process variables on the micromeritic and physicochemical properties of spray-dried porous microparticles, part i: Introduction of a new morphology classification system. J. Pharm. Pharmacol. 2012, 64, 1570-1582. [CrossRef] [PubMed]

61. Ógáin, O.N.; Li, J.; Tajber, L.; Corrigan, O.I.; Healy, A.M. Particle engineering of materials for oral inhalation by dry powder inhalers. I-Particles of sugar excipients (trehalose and raffinose) for protein delivery. Int. J. Pharm. 2011, 405, 23-35.

62. Níǵgáin, O.; Tajber, L.; Corrigan, O.I.; Healy, A.M. Spray drying from organic solvents to prepare nanoporous/nanoparticulate microparticles of protein: Excipient composites designed for oral inhalation. J. Pharm. Pharmacol. 2012, 64, 1275-1290.

63. Amaro, M.I.; Tajber, L.; Corrigan, O.I.; Healy, A.M. Optimisation of spray drying process conditions for sugar nanoporous microparticles (NPMPs) intended for inhalation. Int. J. Pharm. 2011, 421, 99-109. [CrossRef]

64. Amaro, M.I.; Tewes, F.; Gobbo, O.; Tajber, L.; Corrigan, O.I.; Ehrhardt, C.; Healy, A.M. Formulation, stability and pharmacokinetics of sugar-based salmon calcitonin-loaded nanoporous/nanoparticulate microparticles (npmps) for inhalation. Int. J. Pharm. 2015, 483, 6-18. [CrossRef]

65. Nolan, L.M.; Li, J.; Tajber, L.; Corrigan, O.I.; Healy, A.M. Particle engineering of materials for oral inhalation by dry powder inhalers. II-Sodium cromoglicate. Int. J. Pharm. 2011, 405, 36-46. [CrossRef]

66. Gad, S.; Tajber, L.; Corrigan, O.I.; Healy, A.M. Preparation and characterisation of novel spray-dried nano-structured para-aminosalicylic acid particulates for pulmonary delivery: Impact of ammonium carbonate on morphology, chemical composition and solid state. J. Pharm. Pharmacol. 2012, 64, 1264-1274. [CrossRef]

67. Tewes, F.; Paluch, K.J.; Tajber, L.; Gulati, K.; Kalantri, D.; Ehrhardt, C.; Healy, A.M. Steroid/mucokinetic hybrid nanoporous microparticles for pulmonary drug delivery. Eur. J. Pharm. Biopharm. Offic. J. Arb. Fur Pharm. Verfahr. E.V 2013, 85, 604-613. [CrossRef] 
68. Yamasaki, K.; Kwok, P.C.; Fukushige, K.; Prud'homme, R.K.; Chan, H.K. Enhanced dissolution of inhalable cyclosporine nano-matrix particles with mannitol as matrix former. Int. J. Pharm. 2011, 420, 34-42. [CrossRef] [PubMed]

69. Duret, C.; Wauthoz, N.; Sebti, T.; Vanderbist, F.; Amighi, K. New inhalation-optimized itraconazole nanoparticle-based dry powders for the treatment of invasive pulmonary aspergillosis. Int. J. Nanomed. 2012, 7, 5475-5489. [CrossRef] [PubMed]

70. Pomázi, A.; Buttini, F.; Ambrus, R.; Colombo, P.; Szabó-Révész, P. Effect of polymers for aerolization properties of mannitol-based microcomposites containing meloxicam. Eur. Polym. J. 2013, 49, 2518-2527. [CrossRef]

71. Malamatari, M.; Somavarapu, S.; Bloxham, M.; Buckton, G. Nanoparticle agglomerates of indomethacin: The role of poloxamers and matrix former on their dissolution and aerosolisation efficiency. Int. J. Pharm. 2015, 495, 516-526. [CrossRef]

72. Malamatari, M.; Somavarapu, S.; Kachrimanis, K.; Bloxham, M.; Taylor, K.M.G.; Buckton, G. Preparation of theophylline inhalable microcomposite particles by wet milling and spray drying: The influence of mannitol as a co-milling agent. Int. J. Pharm. 2016, 514, 200-211. [CrossRef]

73. Malamatari, M.; Somavarapu, S.; Kachrimanis, K.; Buckton, G.; Taylor, K.M.G. Preparation of respirable nanoparticle agglomerates of the low melting and ductile drug ibuprofen: Impact of formulation parameters. Powder Technol. 2017, 308, 123-134. [CrossRef]

74. Liu, Q.; Guan, J.; Sun, Z.; Shen, X.; Li, L.; Jin, L.; Mao, S. Influence of stabilizer type and concentration on the lung deposition and retention of resveratrol nanosuspension-in-microparticles. Int. J. Pharm. 2019, 569, 118562. [CrossRef]

75. Teymouri Rad, R.; Dadashzadeh, S.; Vatanara, A.; Alavi, S.; Ghasemian, E.; Mortazavi, S.A. Tadalafil nanocomposites as a dry powder formulation for inhalation, a new strategy for pulmonary arterial hypertension treatment. Eur. J. Pharm. Sci. 2019, 133, 275-286. [CrossRef]

76. Šimková, K.; Joost, B.; Imanidis, G. Production of fast-dissolving low-density powders for improved lung deposition by spray drying of a nanosuspension. Eur. J. Pharm. Biopharm. 2020, 146, 19-31. [CrossRef]

77. Pilcer, G.; Rosière, R.; Traina, K.; Sebti, T.; Vanderbist, F.; Amighi, K. New co-spray-dried tobramycin nanoparticles-clarithromycin inhaled powder systems for lung infection therapy in cystic fibrosis patients. $J$. Pharm. Sci. 2013, 102, 1836-1846. [CrossRef]

78. Leng, D.; Kissi, E.O.; Löbmann, K.; Thanki, K.; Fattal, E.; Rades, T.; Foged, C.; Yang, M. Design of inhalable solid dosage forms of budesonide and theophylline for pulmonary combination therapy. Aaps Pharmscitech 2019, 20, 137. [CrossRef]

79. Leng, D.; Thanki, K.; Foged, C.; Yang, M. Formulating inhalable dry powder using two-fluid and three-fluid nozzle spray drying. Pharm. Res. 2018, 35, 247. [CrossRef]

80. Cipolla, D.; Shekunov, B.; Blanchard, J.; Hickey, A. Lipid-based carriers for pulmonary products: Preclinical development and case studies in humans. Adv. Drug Deliv. Rev. 2014, 75, 53-80. [CrossRef]

81. Ngan, C.L.; Asmawi, A.A. Lipid-based pulmonary delivery system: A review and future considerations of formulation strategies and limitations. Drug Deliv. Transl. Res. 2018, 8, 1527-1544. [CrossRef] [PubMed]

82. Storm, G.; Crommelin, D.J.A. Liposomes: Quo vadis? Pharm. Sci. Technol. Today 1998, 1, 19-31. [CrossRef]

83. Payne, N.I.; Timmins, P.; Ambrose, C.V.; Ward, M.D.; Ridgway, F. Proliposomes: A novel solution to an old problem. J. Pharm. Sci. 1986, 75, 325-329. [CrossRef] [PubMed]

84. Rojanarat, W.; Changsan, N.; Tawithong, E.; Pinsuwan, S.; Chan, H.-K.; Srichana, T. Isoniazid proliposome powders for inhalation-preparation, characterization and cell culture studies. Int. J. Mol. Sci. 2011, 12, 4414-4434. [CrossRef]

85. Patil-Gadhe, A.A.; Kyadarkunte, A.Y.; Pereira, M.; Jejurikar, G.; Patole, M.S.; Risbud, A.; Pokharkar, V.B. Rifapentine-proliposomes for inhalation: In vitro and in vivo toxicity. Toxicol. Int. 2014, 21, 275-282.

86. Ye, T.; Sun, S.; Sugianto, T.D.; Tang, P.; Parumasivam, T.; Chang, Y.K.; Astudillo, A.; Wang, S.; Chan, H.K. Novel combination proliposomes containing tobramycin and clarithromycin effective against pseudomonas aeruginosa biofilms. Int. J. Pharm. 2018, 552, 130-138. [CrossRef]

87. Weber, S.; Zimmer, A.; Pardeike, J. Solid lipid nanoparticles (sln) and nanostructured lipid carriers (nlc) for pulmonary application: A review of the state of the art. Eur. J. Pharm. Biopharm. 2014, 86, 7-22. [CrossRef] 
88. Gaspar, D.P.; Faria, V.; Gonçalves, L.M.D.; Taboada, P.; Remuñán-López, C.; Almeida, A.J. Rifabutin-loaded solid lipid nanoparticles for inhaled antitubercular therapy: Physicochemical and in vitro studies. Int. J. Pharm. 2016, 497, 199-209. [CrossRef] [PubMed]

89. Honmane, S.; Hajare, A.; More, H.; Osmani, R.A.M.; Salunkhe, S. Lung delivery of nanoliposomal salbutamol sulfate dry powder inhalation for facilitated asthma therapy. J. Liposome Res. 2019, 29, 332-342. [CrossRef]

90. Cipolla, D.; Wu, H.; Salentinig, S.; Boyd, B.; Rades, T.; Vanhecke, D.; Petri-Fink, A.; Rothin-Rutishauser, B.; Eastman, S.; Redelmeier, T.; et al. Formation of drug nanocrystals under nanoconfinement afforded by liposomes. RSC Adv. 2016, 6, 6223-6233. [CrossRef]

91. Khatib, I.; Khanal, D.; Ruan, J.; Cipolla, D.; Dayton, F.; Blanchard, J.D.; Chan, H.K. Ciprofloxacin nanocrystals liposomal powders for controlled drug release via inhalation. Int. J. Pharm. 2019, 566, 641-651. [CrossRef]

92. Sur, S.; Rathore, A.; Dave, V.; Reddy, K.R.; Chouhan, R.S.; Sadhu, V. Recent developments in functionalized polymer nanoparticles for efficient drug delivery system. Nano Struct. Nano Obj. 2019, 20, 100397. [CrossRef]

93. Lebhardt, T.; Roesler, S.; Beck-Broichsitter, M.; Kissel, T. Polymeric nanocarriers for drug delivery to the lung. J. Drug Deliv. Sci. Technol. 2010, 20, 171-180. [CrossRef]

94. Ohashi, K.; Kabasawa, T.; Ozeki, T.; Okada, H. One-step preparation of rifampicin/poly(lactic-co-glycolic acid) nanoparticle-containing mannitol microspheres using a four-fluid nozzle spray drier for inhalation therapy of tuberculosis. J. Control. Release 2009, 135, 19-24. [CrossRef]

95. Wang, Z.; Cuddigan, J.L.; Gupta, S.K.; Meenach, S.A. Nanocomposite microparticles (ncmp) for the delivery of tacrolimus in the treatment of pulmonary arterial hypertension. Int. J. Pharm. 2016, 512, 305-313. [CrossRef]

96. Wang, Z.; Gupta, S.K.; Meenach, S.A. Development and physicochemical characterization of acetalated dextran aerosol particle systems for deep lung delivery. Int. J. Pharm. 2017, 525, 264-274. [CrossRef]

97. Wang, Z.; Meenach, S.A. Optimization of acetalated dextran-based nanocomposite microparticles for deep lung delivery of therapeutics via spray-drying. J. Pharm. Sci. 2017, 106, 3539-3547. [CrossRef]

98. Rezazadeh, M.; Davatsaz, Z.; Emami, J.; Hasanzadeh, F.; Jahanian-Najafabadi, A. Preparation and characterization of spray-dried inhalable powders containing polymeric micelles for pulmonary delivery of paclitaxel in lung cancer. J. Pharm. Pharm. Sci. A Publ. Can. Soc. Pharm. Sci. Soc. Can. Des Sci. Pharm. 2018, 21, 200s-214s. [CrossRef]

99. Farhangi, M.; Mahboubi, A.; Kobarfard, F.; Vatanara, A.; Mortazavi, S.A. Optimization of a dry powder inhaler of ciprofloxacin-loaded polymeric nanomicelles by spray drying process. Pharm. Dev. Technol. 2019, 24, 584-592. [CrossRef] [PubMed]

100. Li, X.; Anton, N.; Arpagaus, C.; Belleteix, F.; Vandamme, T.F. Nanoparticles by spray drying using innovative new technology: The büchi nano spray dryer b-90. J. Control Release 2010, 147, 304-310. [CrossRef] [PubMed]

101. Arpagaus, C.; Collenberg, A.; Rütti, D.; Assadpour, E.; Jafari, S.M. Nano spray drying for encapsulation of pharmaceuticals. Int. J. Pharm. 2018, 546, 194-214. [CrossRef] [PubMed]

102. Chan, H.K.; Kwok, P.C. Production methods for nanodrug particles using the bottom-up approach. Adv. Drug Deliv. Rev. 2011, 63, 406-416. [CrossRef]

103. Bürki, K.; Jeon, I.; Arpagaus, C.; Betz, G. New insights into respirable protein powder preparation using a nano spray dryer. Int. J. Pharm. 2011, 408, 248-256. [CrossRef]

104. Schoubben, A.; Giovagnoli, S.; Tiralti, M.C.; Blasi, P.; Ricci, M. Capreomycin inhalable powders prepared with an innovative spray-drying technique. Int. J. Pharm. 2014, 469, 132-139. [CrossRef]

105. Merchant, Z.; Taylor, K.M.; Stapleton, P.; Razak, S.A.; Kunda, N.; Alfagih, I.; Sheikh, K.; Saleem, I.Y.; Somavarapu, S. Engineering hydrophobically modified chitosan for enhancing the dispersion of respirable microparticles of levofloxacin. Eur. J. Pharm. Biopharm. Offic. J. Arb. Fur Pharm. Verfahr. E.V 2014, 88, 816-829. [CrossRef]

106. Kaewjan, K.; Srichana, T. Nano spray-dried pyrazinamide-l-leucine dry powders, physical properties and feasibility used as dry powder aerosols. Pharm. Dev. Technol. 2016, 21, 68-75. [CrossRef]

107. Tabernero, A.; Martín del Valle, E.M.; Galán, M.A. Supercritical fluids for pharmaceutical particle engineering: Methods, basic fundamentals and modelling. Chem. Eng. Process. Process Intensif. 2012, 60, 9-25. [CrossRef]

108. Aguiar-Ricardo, A. Building dry powder formulations using supercritical co2 spray drying. Curr. Opin. Green Sustain. Chem. 2017, 5, 12-16. [CrossRef]

109. Costa, C.; Casimiro, T.; Aguiar-Ricardo, A. Optimization of supercritical co2-assisted atomization: Phase behavior and design of experiments. J. Chem. Eng. Data 2018, 63, 885-896. [CrossRef] 
110. Silva, A.S.; Sousa, A.M.; Cabral, R.P.; Silva, M.C.; Costa, C.; Miguel, S.P.; Bonifácio, V.D.B.; Casimiro, T.; Correia, I.J.; Aguiar-Ricardo, A. Aerosolizable gold nano-in-micro dry powder formulations for theragnosis and lung delivery. Int. J. Pharm. 2017, 519, 240-249. [CrossRef] [PubMed]

111. Silva, M.C.; Silva, A.S.; Fernandez-Lodeiro, J.; Casimiro, T.; Lodeiro, C.; Aguiar-Ricardo, A. Supercritical $\mathrm{CO}_{2}$-assisted spray drying of strawberry-like gold-coated magnetite nanocomposites in chitosan powders for inhalation. Materials 2017, 10, 74. [CrossRef]

112. Restani, R.B.; Conde, J.; Pires, R.F.; Martins, P.; Fernandes, A.R.; Baptista, P.V.; Bonifácio, V.D.; Aguiar-Ricardo, A. Poxylated polyurea dendrimers: Smart core-shell vectors with ic50 lowering capacity. Macromol. Biosci. 2015, 15, 1045-1051. [CrossRef] [PubMed]

(C) 2020 by the authors. Licensee MDPI, Basel, Switzerland. This article is an open access article distributed under the terms and conditions of the Creative Commons Attribution (CC BY) license (http://creativecommons.org/licenses/by/4.0/). 